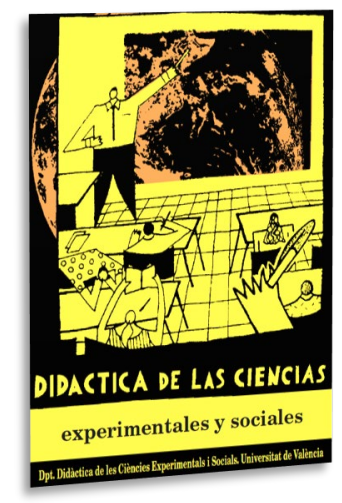

\title{
La transición española: ¿qué sabe el alumnado de 1 o de bachillerato?
}

\author{
The Spanish transition: What do first-year \\ High School students know?
}

DOI: $10.7203 / D C E S .38 .13700$

\author{
Mikel Bueno Urritzelki \\ Universidad Pública de Navarra - Nafarroako Unibertsitate Publikoa (UPNA-NUP) \\ mikel.bueno@unavarra.es \\ ORCID iD: https://orcid.org/0000-0002-5348-8930 \\ Elorri Arcocha Mendinueta \\ Universidad Pública de Navarra - Nafarroako Unibertsitate Publikoa (UPNA-NUP) \\ elorri.arcocha@unavarra.es
}

\begin{abstract}
RESUMEN: El presente artículo es el resultado del análisis de una encuesta realizada a 79 estudiantes de $1^{\circ}$ de Bachillerato sobre la transición española. Mediante esta investigación se quiere acreditar, con metodología cuantitativa, los conocimientos e ideas que el alumnado encuestado tiene acerca de ese periodo histórico tras la realización de la Educación Secundaria. Para ello se ha realizado una encuesta con variedad de preguntas entre las cuales se han incluido algunas relacionadas entre sí para comprobar posibles contradicciones en las respuestas. La encuesta abarca diferentes cuestiones: desde personajes históricos hasta actores más globales como diferentes organizaciones o movilizaciones sociales. El estudio revela que para el alumnado encuestado la transición fue un periodo violento, aunque se comprueban también ciertas contradicciones en su conocimiento sobre este periodo.
\end{abstract}

Palabras ClaVe: transición española, Bachillerato, alumnado, encuesta, conocimientos.

ABSTRACT: The present article is the result of the analysis of a survey conducted among 79 first-year High School students about the Spanish transition. Through this research, we want to assess, with a quantitative methodology, the knowledge and ideas that the surveyed students have about this historical period after the completion of Secondary Education. A survey was conducted with a variety of questions, among which are included some interrelated to check possible contradictions in the answers. The survey covers different issues: from historical figures to more global actors such as different organizations or social mobilizations. This study reveals that surveyed students think that the transition was a violent period, although there are also some contradictions in their knowledge of this period.

KEYWORDS: Spanish transition, High School, students, survey, knowledge.

Fecha de recepción: enero de 2019 Fecha de aceptación: septiembre de 2019

Agradecemos el apoyo efectuado por el Grupo de Investigación UPNA-315 "Historia y Economía" de la Universidad Pública de Navarra, dirigido por el profesor José Miguel Lana Berasain. 


\section{INTRODUCCIÓN}

Cuando se planteó esta investigación uno de los inconvenientes que se veía era que existía una posibilidad muy alta de que el alumnado desconociese por completo el tema que se planteaba, debido a la escasa o nula formación que habrían recibido durante la Educación Secundaria Obligatoria (ESO), y también porque, aún habiendo recibido esa formación, la hubiesen olvidado por completo. Así lo indicaron varios docentes del Centro Educativo en donde se realizó la encuesta. No obstante, pese a que la hipótesis inicial pudo ser que el desconocimiento iba ser la tónica general, se decidió que no iba a haber una hipótesis apriorística. Si realmente existía una gran ignorancia respecto del tema eso también daría información con la cual trabajar; si por el contrario se observaba que sí existían conocimientos o ideas previas por parte del alumnado se trabajaría analizando los datos extraídos de las encuestas realizadas. El caso resultante ha sido, afortunadamente, el segundo.

En consecuencia, los objetivos que se plantean en esta investigación son los siguientes:

1. Recabar información sobre los conocimientos que el alumnado de $1^{\circ}$ de Bachillerato tiene acerca del periodo histórico de la transición española.

2. Comprobar las diferencias existentes en las respuestas según la procedencia territorial del alumnado o de su familia.

\section{AProXimación al MARCo TEÓRICO}

La metodología llevada a cabo para la realización de las encuestas en donde además de los conocimientos que puedan tener las personas encuestadas, se pregunta tanto la identidad de género como el origen de los progenitores. Ambas preguntas se han propuesto con el fin de poder comparar resultados en función del género de la persona, así como también para comprobar si existen diferencias significantes a la hora de responder a las preguntas planteadas en función del origen del alumnado. Debido a que se ha comprobado la irrelavancia de la variable del género en las respuestas se ha procedido a omitirla en el presente artículo.

La variable del origen del alumnado es importante a la hora de las respuestas que se puede realizar, debido a que, tal y como se ha observado en la encuesta, aquellas varían de forma notable; por ejemplo quienes son de origen extranjero, sobre todo africano tienen un conocimiento mínimo, si no nulo, de la transición española. Del mismo modo, se ha querido comprobar si quienes son de origen navarro o vasco-navarro tienen diferentes respuestas que quienes tienen uno o dos de los progenitores de otras zonas del Estado español.

Obviamente la variable de origen no es la única que puede determinar una respuesta $u$ otra. Existen multitud de variables que pueden influir, como pueden ser la ideología de los padres y madres, el nivel socio-cultural, el nivel económico, etc. Sin embargo, no se han analizado estas u otras variables por lo que quedaría pendiente para futuras investigaciones que se pudiesen realizar.

El cuestionario que se entregó al alumnado constaba de un total de 25 preguntas, algunas de las cuales eran cruzadas con el fin de comprobar posibles contradicciones o respuestas automáticas, esto es que el alumnado contestase sin reflexionar. El volcado de los datos obtenidos se ha realizado mediante tablas dinámicas, las cuales permiten tanto el análisis de aquellos como su cotejo.

Asimismo, se parte de la concepción de que el periodo histórico de la transición española no fue pacífico ni tampoco democrático, debido a que se trató de un periodo realmente violento, tanto por la violencia ejercida por diferentes organizaciones armadas de izquierda revolucionario y/o independentistas, así como por la violencia ejercida por el Estado, bien a través de las Fuerzas de Seguridad, o bien a través de organizaciones de extrema derecha, tal y como ha demostrado la historiografía reciente (Casanella, 2014; Rodríguez, 2015; Bueno, 2016; Casals, 2016; Wilhlemi, 2016). Del mismo modo, y pese al debate historiográfico existente en torno a la delimitación temporal de este periodo histórico, la cronología de la transición española se ha enmarcado entre la aprobación de la Ley de Reforma Política en noviembre de 1976 y el referéndum de la Constitución de 1978. Se han decidido estas fechas por ser la primera el inicio del derrumbe controlado de la legislación 
franquista, mientras que la segunda marca el comienzo de un nuevo régimen político vigente hasta la actualidad.

\subsection{Muestra}

Se debe tener en cuenta que se trata de una investigación cuantitativa, debido a que se trata de un estudio a escala reducida. Para llevar a cabo esta investigación se realizó la encuesta al alumnado de $1^{\circ}$ de Bachillerato del Instituto de Enseñanza de Secundaria Barañain, situado en la localidad navarra de Barañain. El cuestionario fue rellenado por un total de 79 personas (41 chicas y 38 chicos) que cursan los diferentes bachilleratos ofertados en el Centro, por lo que no se ha llevado a cabo ninguna distinción en función de los estudios que están realizando en el momento de realizar la encuesta. Esto ha sido así debido a que, indiferentemente de la opción que se curse en bachillerato, todas las personas encuestadas han estudiado el mismo temario de historia en 4 de E.S.O.

Lo ideal hubiese sido poder realizar la encuesta a todo el alumnado de $1^{\circ}$ y $2^{\circ}$ de Bachillerato para poder tener así una visión más amplia. No obstante, debido a que por diferentes cuestiones no se pudo acceder al alumnado de $2^{\circ}$, el cuestionario se circunscribe únicamente al de $1^{\circ}$.

GRÁFICO 1. Distribución de las personas encuestadas por origen

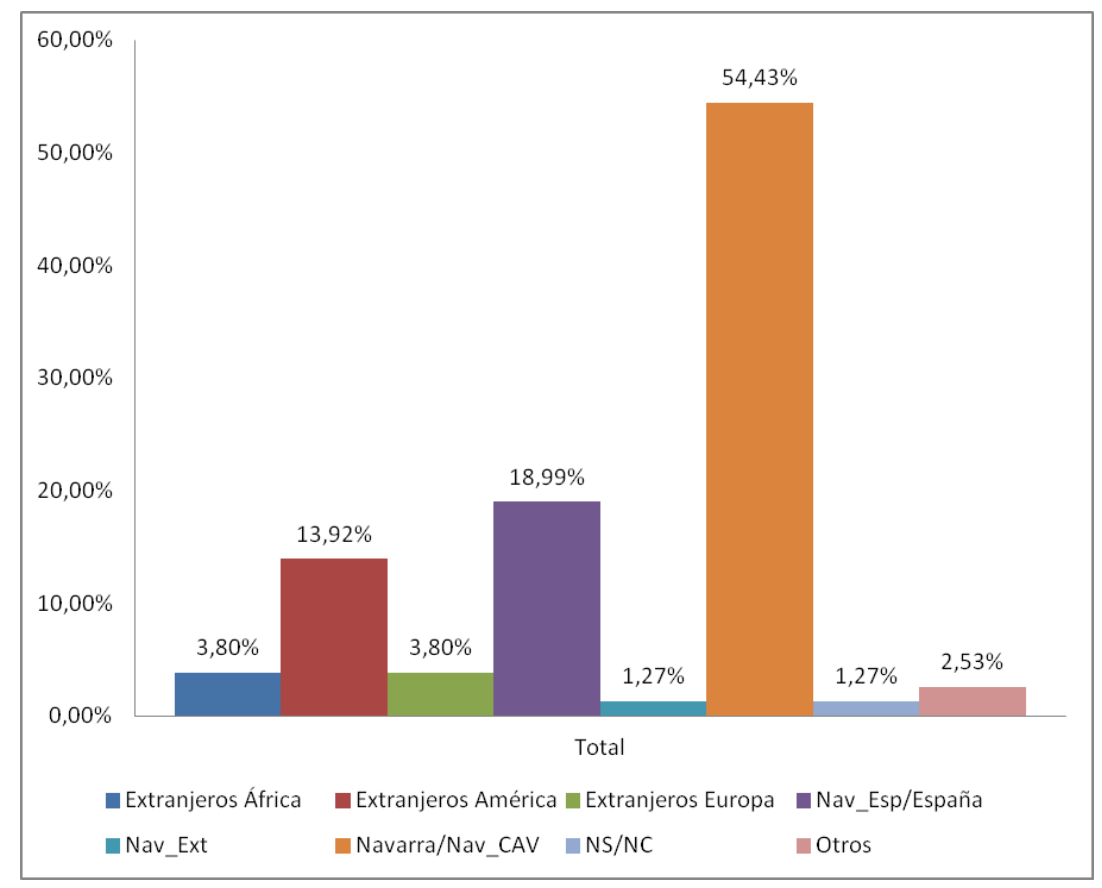

Fuente: Elaboración propia.

Como ya se ha indicado y puede comprobarse en el Gráfico 1, la encuesta se ha realizado a 79 personas, de las cuales el 51,9\% son de género femenino ( 41 chicas) y el 48,1\% de género masculino (38 chicos). Por origen, en el 54,43\% del total sus progenitores son ambos de Navarra o uno de Navarra y el otro de la Comunidad Autónoma Vasca (CAV). Se ha realizado este agrupamiento debido a que se quería constatar si existe algún tipo de diferencia a la hora de responder entre este grupo y los restantes. Este grupo, por lo tanto, es el mayoritario entre las personas encuestadas.

El segundo grupo, con un 18,99\% del total, es el que ambos progenitores son del Estado español y/o uno de ellos de Navarra; es decir, o los dos son de otros territorios del Estado (que no sean los del primer grupo) o uno de ellos es de Navarra y el otro de otra parte del Estado a excepción de la CAV. El tercer gran grupo, siendo el 13,92\%, corresponde a las personas cuyos progenitores, los dos, provienen de diversos países de América. Para concluir, se debe señalar que existen más grupos, los cuales también se tienen en cuenta durante el estudio, pero que son prácticamente residuales. Las 
personas de origen africano o europeo son el 3,8\% en ambos casos; así como un 1,27\% siendo uno de los ascendientes de Navarra y el otro del extranjero; un 2,53\% que no se engloba en ninguno de los grupos creados; y un 1,27\% que no respondió.

Para analizar con criterio científico los conocimientos o ideas que el alumnado de $1^{\circ}$ de Bachillerato tiene acerca de la transición española, lo primero que se les pidió a las personas encuestadas fue que indicasen dónde habían obtenido algún tipo de información sobre dicho periodo histórico. Para ello podían indicar las opciones que considerasen apropiadas para su caso. Tal y como se puede observar en el siguiente gráfico, de las 79 personas encuestas, 62 han indicado al instituto como una de sus fuentes de información; los medios de comunicación y las series y películas son otra fuente que han indicado 35 personas. Llama la atención que únicamente 17 personas saben algo de la transición por conversaciones familiares.

GRÁFICO 2. Señala en dónde has obtenido algún tipo de información sobre la transición española.

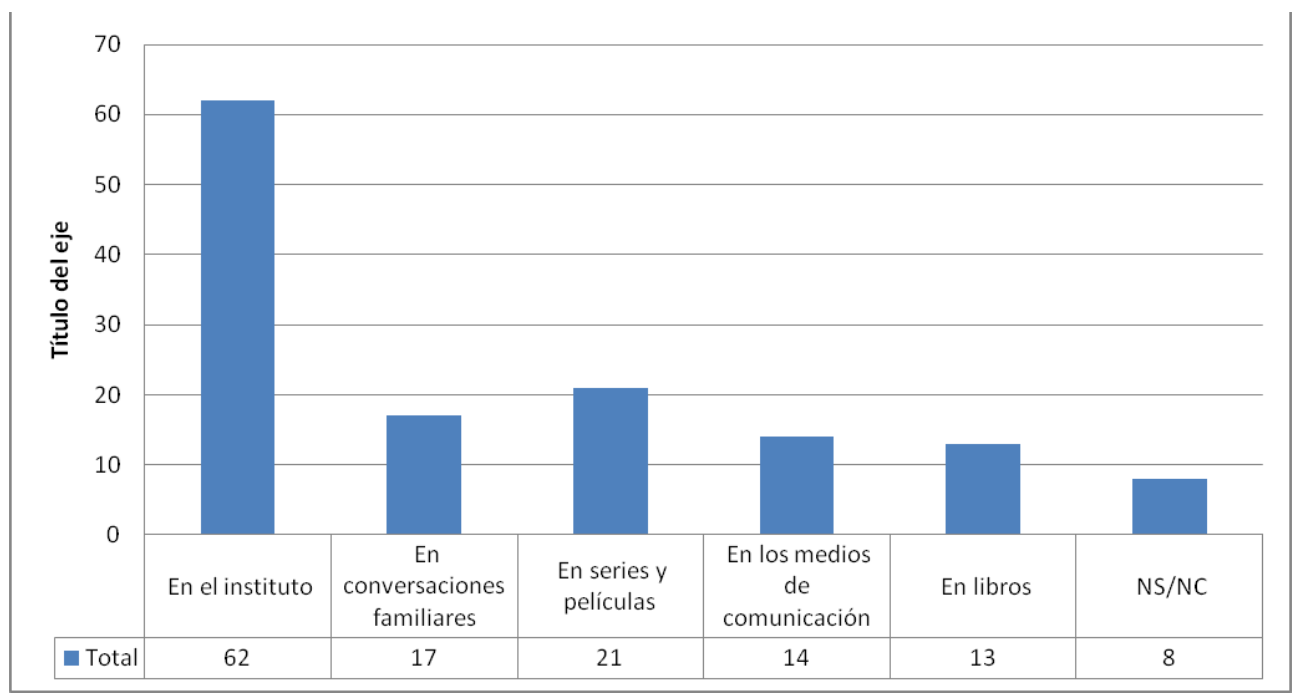

Fuente: Elaboración propia.

El análisis del Gráfico 2 arroja una conclusión evidente: es en el instituto donde la inmensa mayoría recibe la formación sobre la transición española y dónde pueden formarse unos conocimientos e ideas sobre esta. Sería iluso obviar que los medios de comunicación y las producciones televisivas o cinematográficas no son creadoras de opinión; es más, cualquiera que vea aquellas puede comprobar que el espíritu crítico y la visión científica sobre la transición son prácticamente nulos, y que lo que se proyecta es una visión ideológica claramente favorable sobre este periodo histórico y sobre determinados personajes (Pinilla, 2017; Bardavío, 2017; Cebrián, 2017; Pegenaute, 2017; López, 2017).

No obstante, una fuente de información más cercana es la que se puede recibir a través de las vivencias y opiniones de los diferentes miembros de la familia. Qué vivieron, cómo lo vivieron, qué recuerdos tienen, qué opiniones... Sin embargo, esta es un arma de doble filo. Por un lado estaría la visión, los recuerdos y la ideología del familiar; por el otro el proceso histórico en sí. Es decir, la dicotomía entre historia y memoria, cuestión que escapa a los propósitos de este trabajo pero que tiene gran importancia.

Asimismo, se observa que 13 personas han indicado que también han obtenido información a través de diferentes libros; no se puede saber si son de carácter histórico, si son novelas o de otro tipo, debido a que no se preguntaba por ello. Lo que sí se puede corroborar es que la lectura, al menos en este tema, es la fuente con menor puntuación.

En definitiva, el único lugar donde el alumnado puede obtener una formación científica y crítica sobre la transición española es en los centros educativos. Bien es cierto, y sería ingenuo pensar lo contrario, que el sistema educativo está pensado para responder a los intereses sociales, políticos, 
ideológicos y económicos del Estado que lo desarrolla. No lo es menos que ese mismo sistema educativo tiene resortes por los cuales introducir una enseñanza de la historia mediante la cual sea el propio alumnado quien saque sus propias conclusiones. Pero para ello se debe explicar las diferentes visiones que existen en la historiografía actual, alejándose de la interpretación única y acrítica.

\section{LA TRANSICIÓN ESPAÑOLA SEGÚN EL ALUMNADO: REFORMA, VIOLENTA Y DEMOCRÁTICA}

La primera sorpresa al volcar los datos de la encuesta aparece con la primera pregunta que entra en materia. Tradicionalmente, y los medios de comunicación han sido muy importantes en este sentido, se ha presentado la transición española como un periodo de consenso. Es más, consenso es el término que habitualmente se utiliza para definir ese tiempo. Además, también se ha destacado, por activa y por pasiva, el carácter pacífico de la transición llegando a ser calificada como modélica histórico (Maravall, 1989; Powell, 2002; Preston, 2001; Redero San Román, 1993, 1996; Rivera, 1998; Soto, 1996; Tezanos, 1989; Tusell, 1991). Sin embargo, si se observa el Gráfico 3, podemos comprobar que la idea que tienen las personas encuestadas es totalmente opuesta. Los dos términos que menos votos tienen a la hora de definir la transición española son, precisamente, consenso y pacífica. Por el contrario, los que más votos han obtenido son, de más a menos: reforma, violenta y democrática.

GRÁFICO 3. Elige tres términos que, según tú, definan el periodo de la transición.

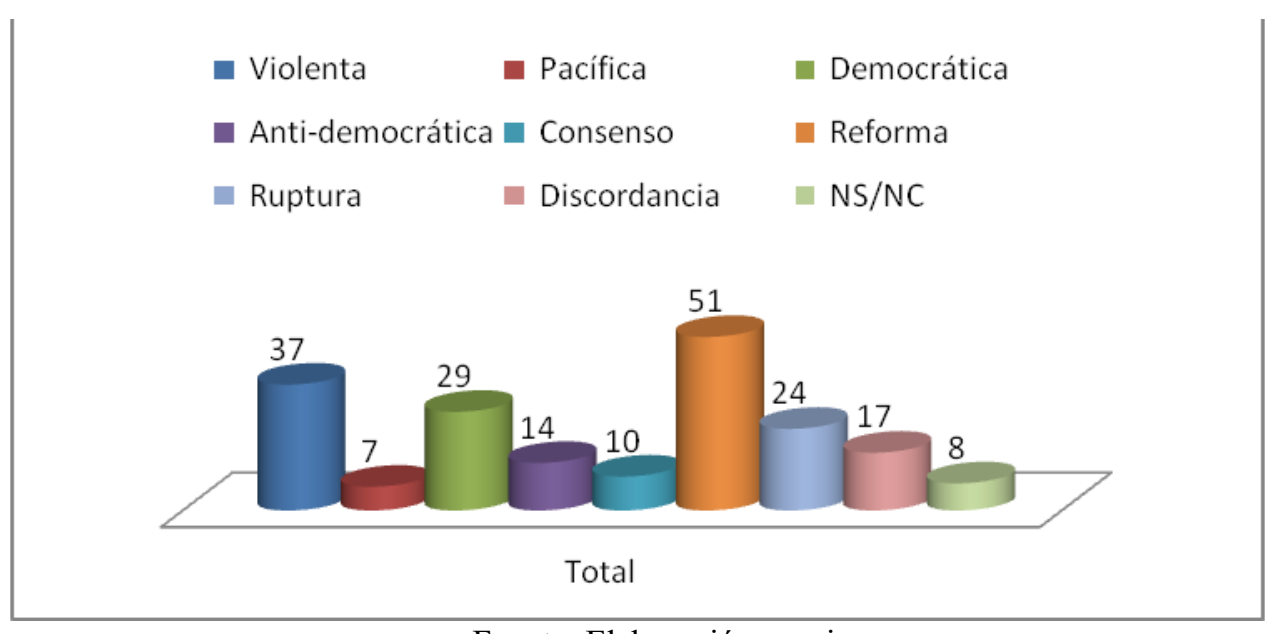

Fuente: Elaboración propia.

Reforma es el término con el que, mayoritariamente, definen la transición. Si realmente entienden que definir de esta manera dicho periodo supone que el régimen político actual viene producido desde y por la dictadura, supondría un análisis histórico de envergadura. Sin embargo, tal y como se verá más adelante, esto no resulta así ya que existen grandes contradicciones entre unas respuestas y otras. Una de ellas se produce en esta misma pregunta, y que es comúnmente aceptada: calificar la transición española como democrática. Esto en sí mismo es un oxímoron. Por definición una transición es un cambio, un estado intermedio entre uno que finaliza y otro que comienza (Molinero e Ysàs, 2018). Por lo tanto la transición ni fue ni pudo ser democrática, sino que era "hacia" o "a la" democracia. Es por ello que esta respuesta refleja un desconocimiento terminológico y político.

Dos respuestas muy interesantes son la referente a la definición de violenta, siendo el tercer término con mayor puntuación, y la de pacífica, que es el que menor puntuación obtiene. En este aspecto sí que parece que el alumnado lo tiene mucho más claro. Es más, cuando posteriormente se 
le pregunta si el Estado creó grupos armados ilegales para enfrentarse a sus adversarios políticos, la respuesta es, tal y como se puede ver a continuación, apabullante.

GRÁFICO 4. El Estado creó grupos armados ilegales para enfrentarse a sus adversarios políticos.

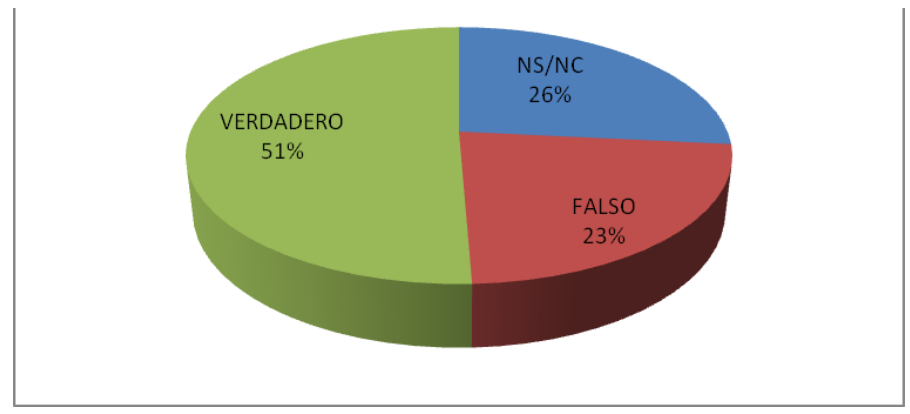

Fuente: Elaboración propia.

GRÁFICO 5. Grupos de ultraderecha y el terrorismo de Estado causaron más de 300 muertes durante la transición.

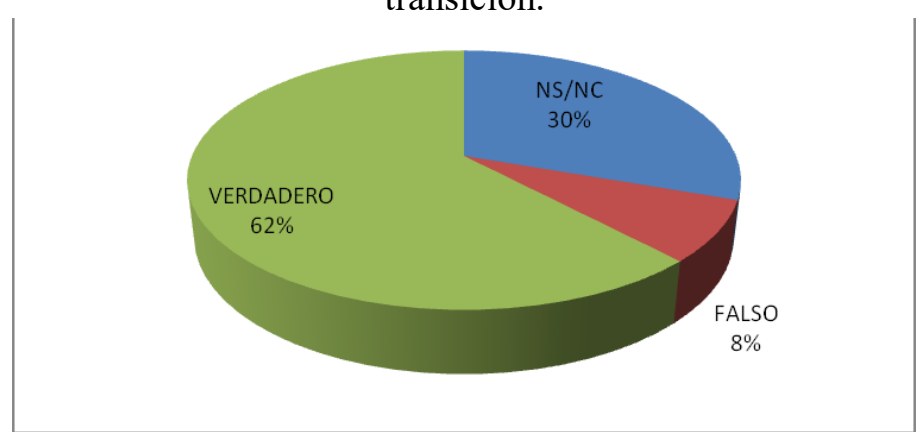

Fuente: Elaboración propia.

Un 51\% afirma que es verdadero que el Estado crease grupos armados ilegales, frente a un 23\% que dice ser falso. Es más, al preguntarles si grupos armados de extrema derecha y el terrorismo de Estado causaron más de 300 muertes durante la transición, un abrumador $62 \%$ dice que es verdadero. Si analizamos la respuesta del Gráfico 4 por origen de las personas entrevistadas se observan cuestiones interesantes -Gráfico 6-.

GRÁFICO 6. El Estado creó grupos armados ilegales para enfrentarse a sus adversarios políticos (respuestas por origen).

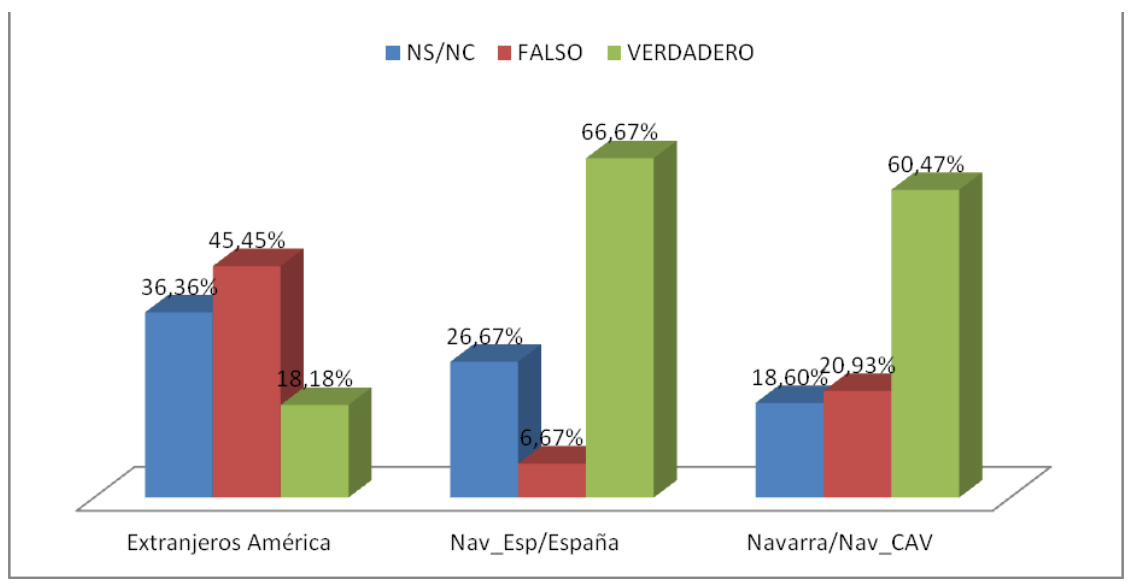

Fuente: Elaboración propia. 
Existe una gran mayoría de quienes, con ambos progenitores procedentes de cualquier territorio del Estado español, creen verdadero que el Estado crease grupos armados ilegales. Sin embargo, entre quienes tienen origen americano las respuestas son, casi, inversas. Si quienes tienen procedencia de Navarra, Comunidad Autónoma Vasca y/u otros territorios del Estado, prácticamente 2/3 afirman que es verdadero que el Estado creó grupos armados para enfrentarse a sus adversarios políticos, menos del $20 \%$ de quienes tienen origen americano lo creen; además, más del $45 \%$ cree que la afirmación es falsa, por un $20 \%$ y menos de un $7 \%$ para los otros dos grupos. Esto podría ser debido a la percepción que se tiene en muchos ámbitos de la sociedad latinoamericana de la transición española, la cual pudo haber sido "importada" en la década de 1980 cuando fueron cayendo las diferentes dictaduras del Cono Sur. No obstante, como se ve en el Gráfico 7 esto no es así; parece más bien producto de la desinformación o, simplemente, una gran contradicción en las respuestas. Esta última afirmación se comprueba en el Gráfico 7 ya que, solo un $9 \%$ dice que es falso que el terrorismo de Estado y grupos de ultraderecha provocasen más de 300 muertes durante la transición. Es decir, se produce un vuelco con respecto al Gráfico 6. Del mismo modo, llama poderosamente la atención que casi un 55\% no sepa o no conteste a la pregunta de las más de 300 muertes, superando en casi 20 puntos la pregunta anterior. Los otros dos grupos seleccionados en el Gráfico 7, afirman mayoritariamente que es verdadera la afirmación, siendo más quienes optan por esta respuesta que en el Gráfico 6.

GRÁFICO 7. Grupos de ultraderecha y el terrorismo de Estado causaron más de 300 muertes durante la transición (respuestas por origen).

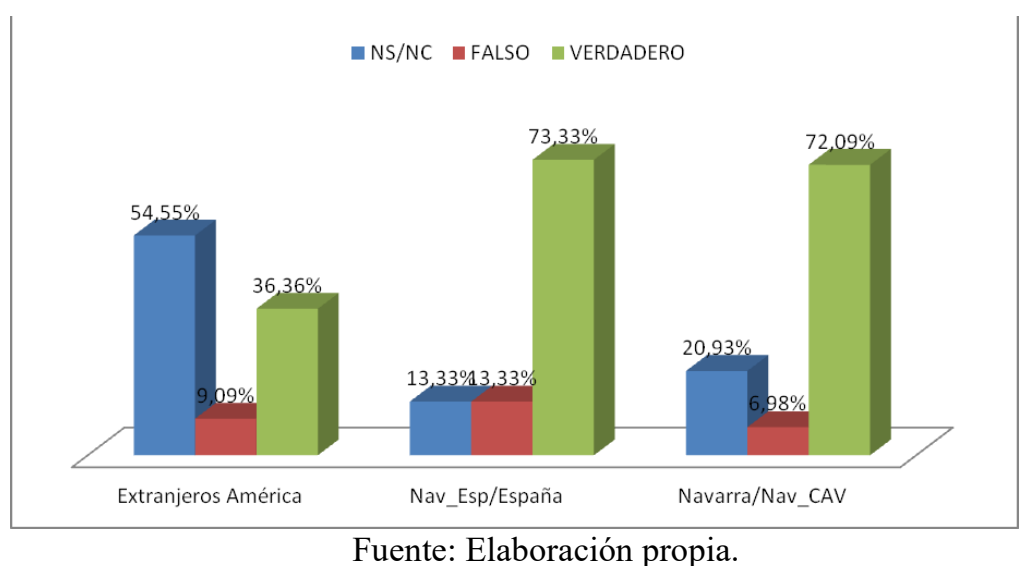

\subsection{Los personajes históricos}

Si como se ha podido comprobar el tema de la violencia estatal es ampliamente compartida por el conjunto de las personas entrevistadas, con las contradicciones ya señaladas, otras cuestiones que debieran ser menos polémicas no quedan nada claras para el alumnado.

Una de estas cuestiones es la que se presenta en el Gráfico 8. Se realizaron dos preguntas que son analizadas conjuntamente; se les dio una lista de nombres y debían indicar quién fue el último presidente del Gobierno de la dictadura; en la siguiente pregunta, con otra lista de nombres, tenían que señalar al primer presidente del Gobierno de la democracia. Obviamente la respuesta en ambas preguntas es la misma: Adolfo Suárez quien fue el último presidente de la dictadura designado por el rey Juan Carlos I, y el primero de la democracia, siendo elegido tras las elecciones generales de 1977, las primeras desde la II República. Únicamente el 3,80\% han contestado correctamente a ambas preguntas. La mayor respuesta que se obtiene, con un $36,71 \%$, es que el último presidente de la dictadura fue Francisco Franco y el primer presidente de la democracia Adolfo Suárez. 
GRÁFICO 8. ¿Quién fue el último presidente del Gobierno de la dictadura? - ¿Quién fue el primer presidente del Gobierno tras el final de la dictadura?

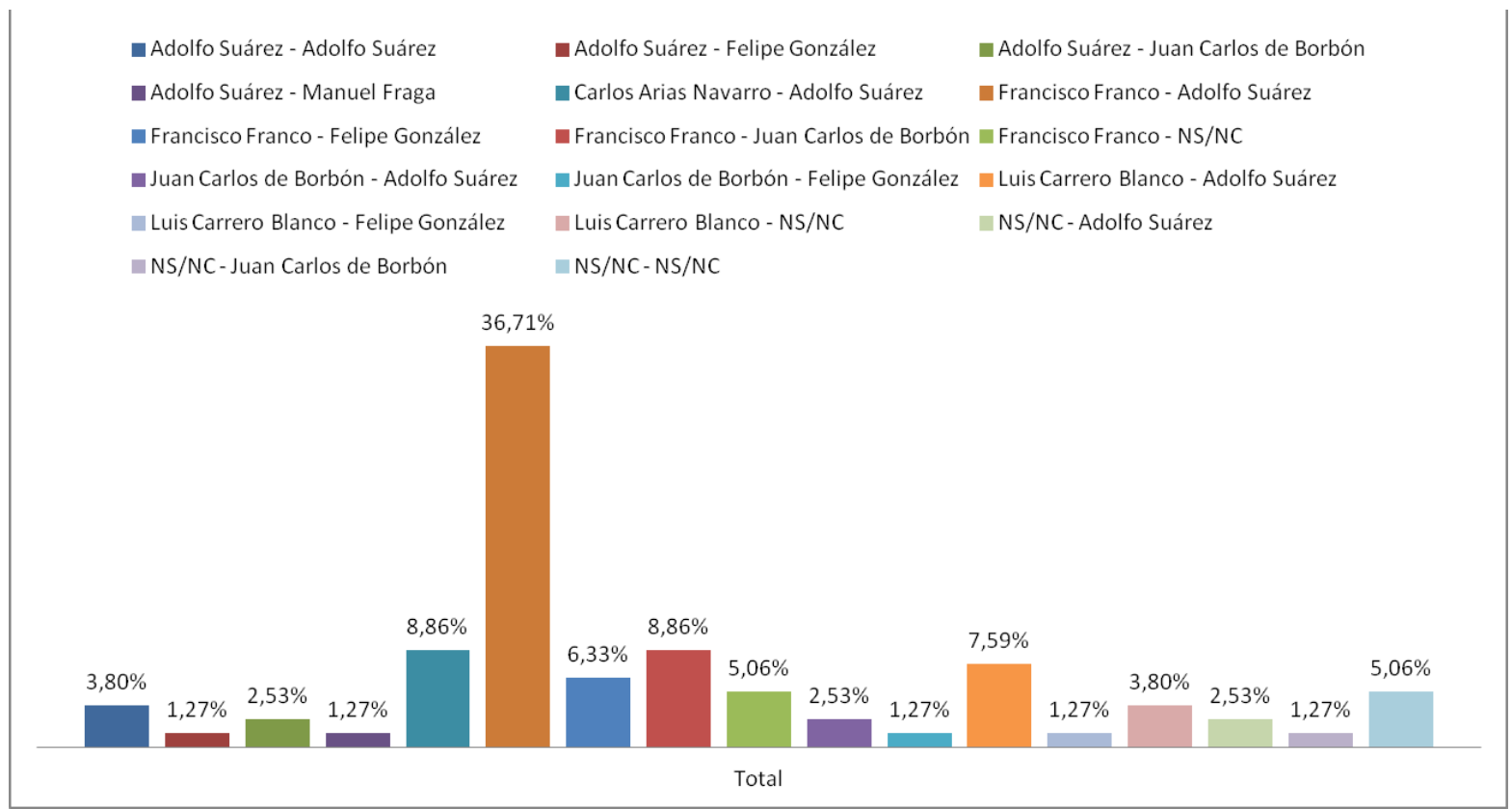

Fuente: Elaboración propia

Del mismo modo existe una gran dispersión existiendo hasta 17 respuestas combinadas diferentes, lo que evidencia una gran confusión a la hora de relacionar a los diferentes personajes históricos con su papel histórico. Un ejemplo de ello es Juan Carlos I, al cual le sitúan como presidente, bien en la dictadura o bien en la democracia, más de un 15\%. Esto puede ser debido a que desconocen la diferencia entre jefe de Gobierno y jefe de Estado, o también al desconocimiento del papel que realmente jugaba el monarca tanto durante la dictadura como en el régimen democrático.

Si observamos los resultados expuestos en los siguientes gráficos -9 y 10 - se llega a dos conclusiones. La primera es que el $62,03 \%$ afirma que Suárez fue el primer presidente de la democracia, mientras que, únicamente un $8,86 \%$ que fue el último de la dictadura. Estos resultados indican la visión de Adolfo Suárez como un político al que se relaciona directamente con el régimen democrático. Esta circunstancia refleja una contradicción con respecto a las respuestas indicadas en el Gráfico 3, en donde se observa que el mayor término con el que definen a la transición es el de reforma. Si realmente supiesen el significado de ese término en el contexto histórico de la transición española lo podrían haber identificado con Suárez. Sin embargo, no ha sido así.

GRÁFICO 9. ¿Quién fue el último presidente del Gobierno de la dictadura?

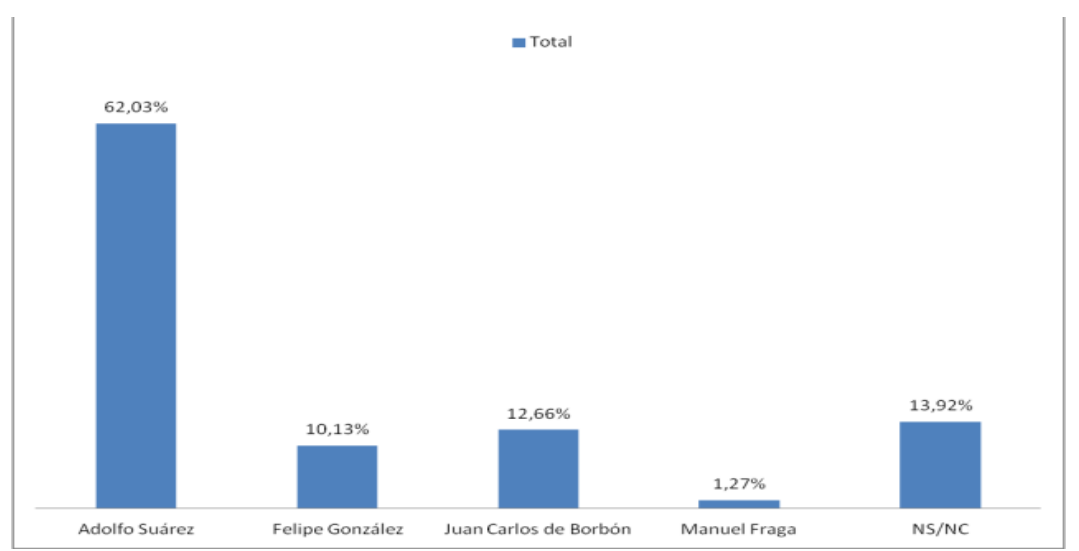

Fuente: Elaboración propia. 
GRÁFICO 10. ¿Quién fue el primer presidente del Gobierno tras el final de la dictadura?

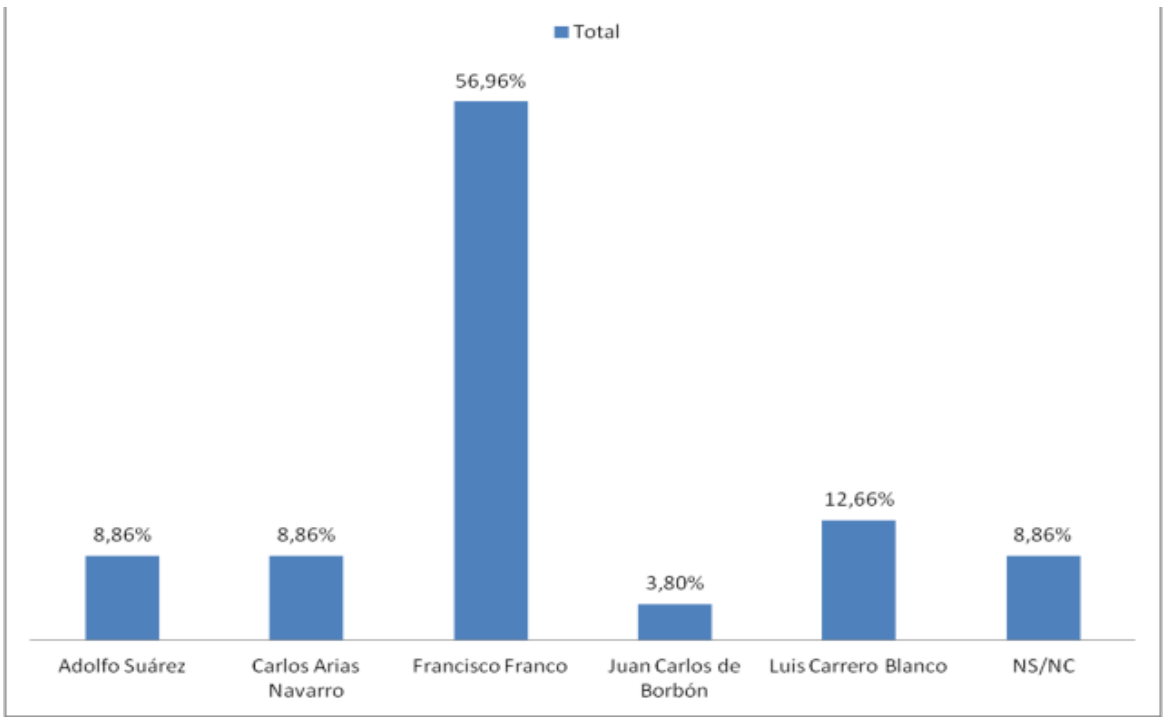

Fuente: Elaboración propia.

La segunda conclusión es la identificación que hace el alumnado entre la dictadura y Franco, ya que casi un $60 \%$ cree que el dictador fue el último presidente del franquismo cuando, como se sabe, dejó la presidencia en 1973. Tras Franco ocuparon la presidencia durante la dictadura Carrero Blanco, Arias Navarro y el propio Suárez.

Este desconocimiento acerca de los diferentes cargos institucionales tiene un reflejo específico en la figura del actual rey emérito Juan Carlos I. Tal y como se ha comprobado anteriormente, más de un 15\% de las personas encuestadas cree que Juan Carlos de Borbón fue presidente del Gobierno, bien durante la dictadura o bien tras ella. No obstante, cuando se les pregunta quién decidió que Juan Carlos fuese rey las respuestas indican también un gran desconocimiento.

GRÁFICO 11. ¿Quién decidió que Juan Carlos I fuese rey de España y Jefe del Estado?

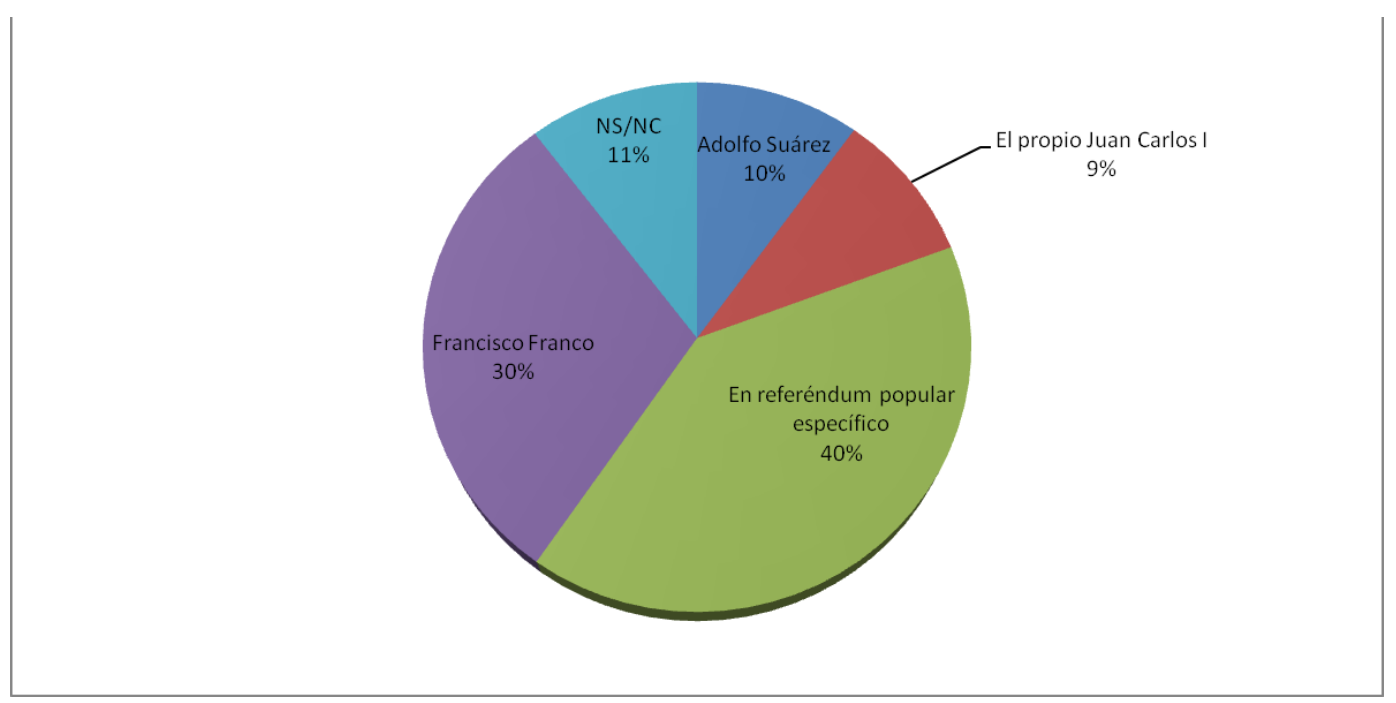

Fuente: Elaboración propia.

Tal y como se puede comprobar en el Gráfico 11 únicamente 3 de cada 10 estudiantes acierta al indicar al dictador Francisco Franco como el responsable de esa decisión. A pesar de ello, si analizamos más detenidamente los resultados se pueden extraer varias conclusiones. La primera de ellas es que la respuesta mayoritaria es la del referéndum específico. Hay que tener en cuenta que en 
las respuestas una de las opciones era "en referéndum popular específico". La importancia radica en el término "específico", ya que si bien la monarquía parlamentaria fue aprobada en el referéndum de la Constitución, tanto aquella como quien debía ser rey nunca fue objeto de consulta popular; en otras palabras, tanto la figura del rey como la monarquía fueron impuestas, en un todo o nada, dentro del referéndum del 6 de diciembre de 1978 (Andrade, 2012; Andre-Bazzana, 2006; Bueno, 2016; Rodríguez, 2015; Wilhelmi, 2016).

Otra conclusión que se puede obtener de las respuestas dadas es que un $49 \%$ constata que la decisión fue realizada por una única persona. Si bien esto es cierto, ya que fue decisión de Franco, para un 19\% del total esa decisión fue tomaba o por Adolfo Suárez o por el propio Juan Carlos I. La visión global es que ese nombramiento no fue de carácter democrático, ya que la decisión unipersonal supera en 9 puntos a la del referéndum. Esta visión que dan los datos, pese a ser correcta, no significa que esté arraigada en el pensamiento de las personas encuestadas.

GRÁFICO 12. ¿Quién decidió que Juan Carlos I fuese rey de España y Jefe del Estado? (respuestas por origen).

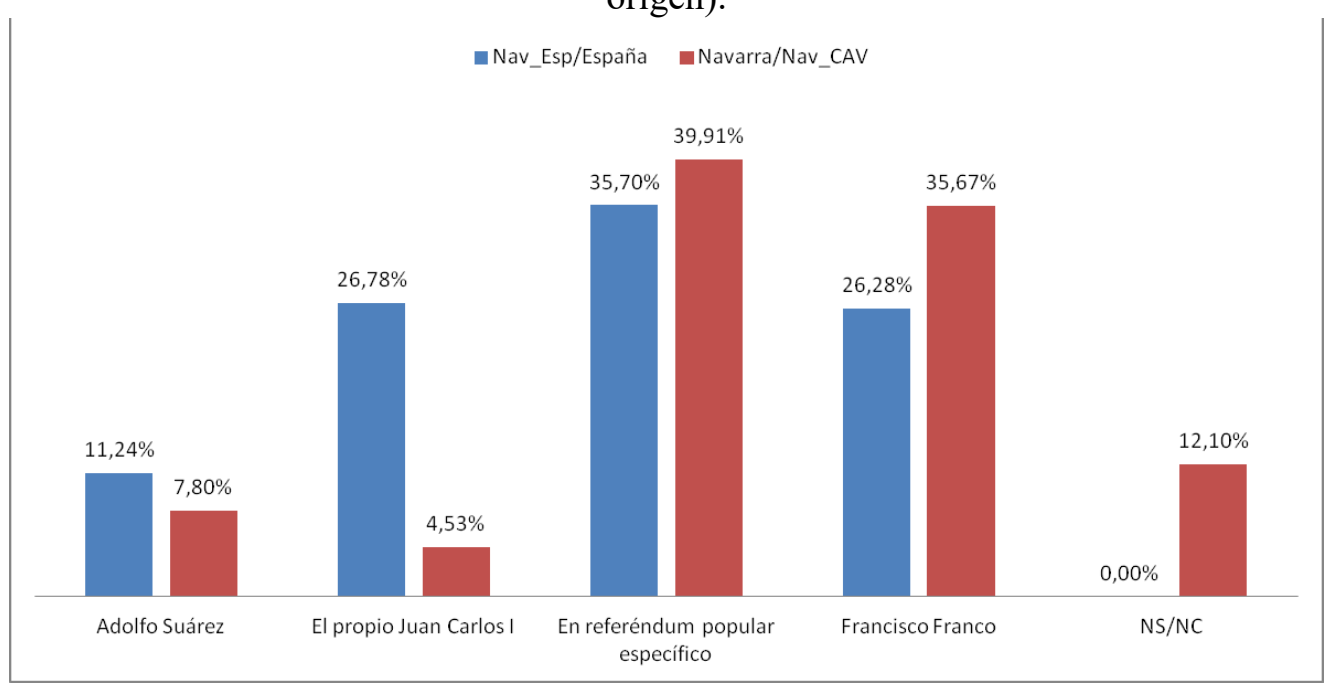

Fuente: Elaboración propia.

Si desglosamos los datos por origen se comprueban diferencias a la hora de responder a la pregunta planteada. Para empezar, de quienes tienen los dos progenitores de Navarra o uno de la $\mathrm{CAV}$, responden correctamente a la pregunta casi un $36 \%$, seis puntos por encima de la media y nueve puntos más que quienes tienen al menos un progenitor del resto del Estado. Asimismo, los primeros superan en cuatro puntos a los segundos a la hora de indicar el referéndum específico como la respuesta correcta, aunque ambos grupos están por debajo de la media en esta respuesta. Dos datos que destacan son, por una parte, que para casi un $27 \%$ de quienes tienen un progenitor de otro territorio del Estado fue el propio Juan Carlos quien se auto-tituló como rey y jefe del Estado, superando así en más de 17 puntos la media; mientras que para el primer grupo lo cree menos del $5 \%$. Por otro parte, más de un $12 \%$ de quienes tienen origen navarro o vasconavarro dicen no saber quién tomó la decisión.

Cuando se les pregunta directamente si creen que fue una decisión popular vía referéndum por lo que se estableció una monarquía parlamentaria y no una república, la polarización es evidente. Para un $43 \%$ sí se decidió en referéndum que el Estado se constituyese como una monarquía parlamentaria, mientras que un $41 \%$ dice que es falso que tal referéndum fuese llevado a cabo. Aquí la clave estaría en saber si ese $43 \%$ cree que mediante el referéndum de la Constitución el pueblo decidió sobre este aspecto o si bien habrá existido otro referéndum para decidir esta cuestión. Si comparamos estas respuestas con las obtenidas en el Gráfico 11, vemos como existe un porcentaje similar entre quienes creen que Juan Carlos I fue nombrado rey y jefe del Estado mediante un referéndum popular específico (un 40\%), y quienes afirman que es verdadero que el Estado español 
es una monarquía parlamentaria, y no una república, por decisión popular. Huelga decir que tal referéndum no se produjo nunca.

GRÁFICO 13. El pueblo decidió en referéndum que el Estado fuese una monarquía parlamentaria y no una república.

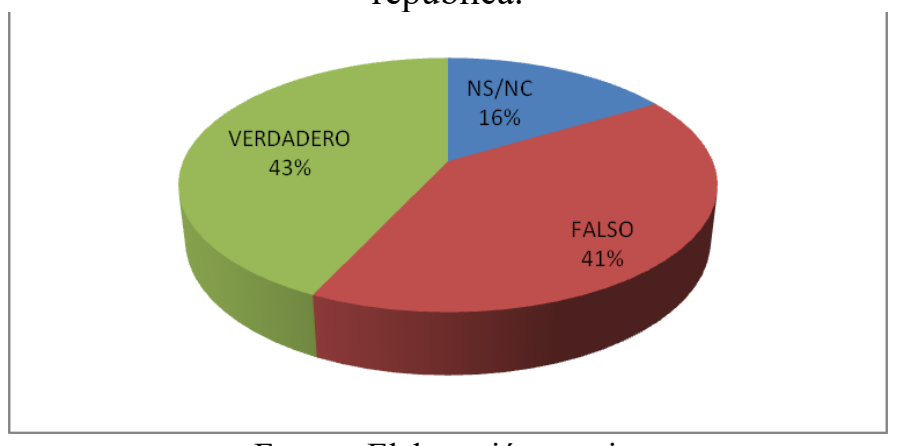

Fuente: Elaboración propia.

Por último, y cerrando este bloque de personajes históricos, se preguntó si Juan Carlos de Borbón tuvo siempre como proyecto político la restauración democrática, y si tanto él como Suárez fueron quienes hicieron posible la transición. Ambas preguntas se realizaron para comprobar cuanto está interiorizado ese discurso sobre la transición que pone a ambos personajes como los artífices de la misma. Para ello, tal y como se puede ver en los dos gráficos siguientes, el alumnado debía indicar una de las cinco opciones al enunciado dado.

GRÁFICO 14. El rey Juan Carlos I siempre tuvo como proyecto político la restauración democrática.

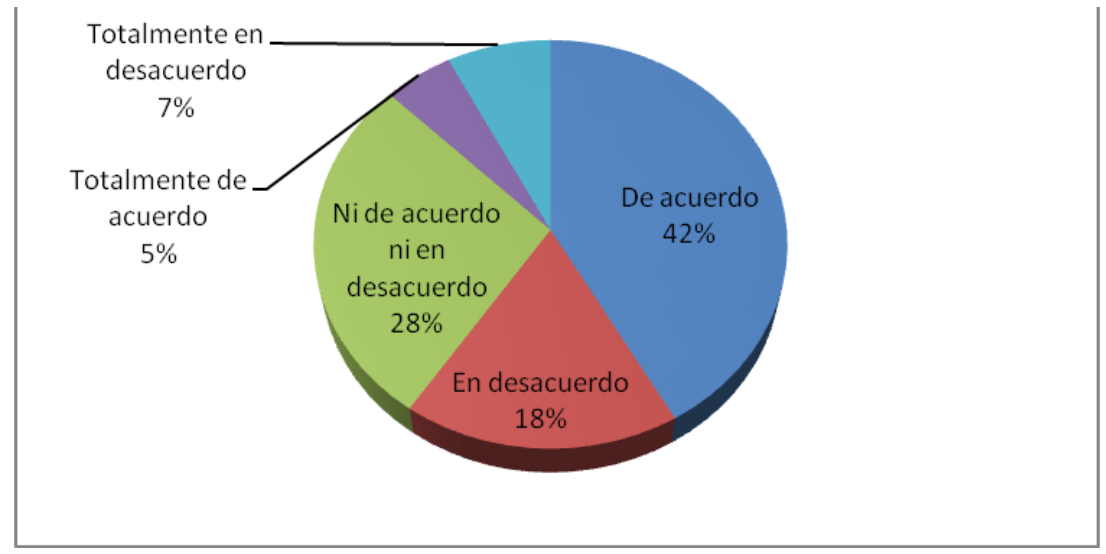

Fuente: Elaboración propia.

GRÁFICO 15. Juan Carlos I y Adolfo Suárez fueron quienes hicieron posible la transición.

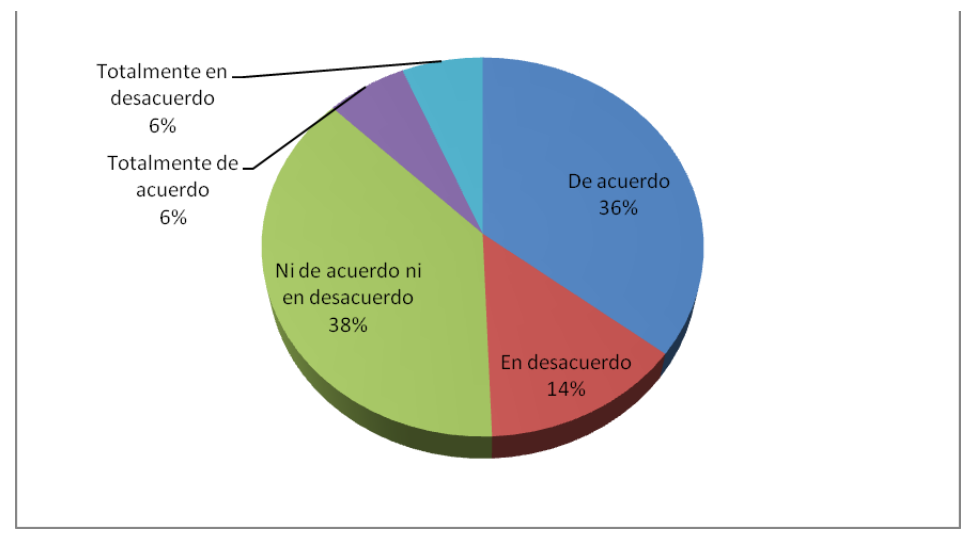

Fuente: Elaboración propia. 
Como se observa en ambos gráficos, en un vistazo general se comprueba que la visión de ambos personajes está ligada al régimen político derivado de la Constitución de 1978. Casi la mitad, un 47\%, está de acuerdo o totalmente de acuerdo que Juan Carlos I siempre tuvo como objetivo político la restauración democrática; por el contrario un $25 \%$ está en desacuerdo o totalmente en desacuerdo ante dicha afirmación. Sin embargo, cuando se les pregunta si creen que lo ocurrido en Portugal con la Revolución de los Claves, o la caída de la dictadura de los coroneles en Grecia fue determinante para que Juan Carlos de Borbón decidiese no reformar la dictadura y acabar con ella, un 43\% responde que es verdadera esa afirmación, por un $22 \%$ que la considera falsa. Por lo tanto, existe una gran contradicción entre las respuestas dadas en la pregunta reflejada en el Gráfico 14 y la del Gráfico 16. Una vez más se comprueba que, tampoco en este apartado, tienen las ideas muy claras. Se puede deducir que existe una idea generalizada que ve al anterior jefe del Estado y a Suárez como promotores de la transición, pero si se hacen preguntas más detalladas esta visión cae o se distorsiona, de manera consciente o inconsciente. Esto se refleja claramente en el siguiente apartado.

GRÁFICo 16. Acontecimientos internacionales (la Revolución de los Claveles en Portugal o la caída de la Dictadura de los Coroneles en Grecia) fueron determinantes para que personajes como Juan Carlos I, optasen por no reformar la dictadura y acabar con esta.

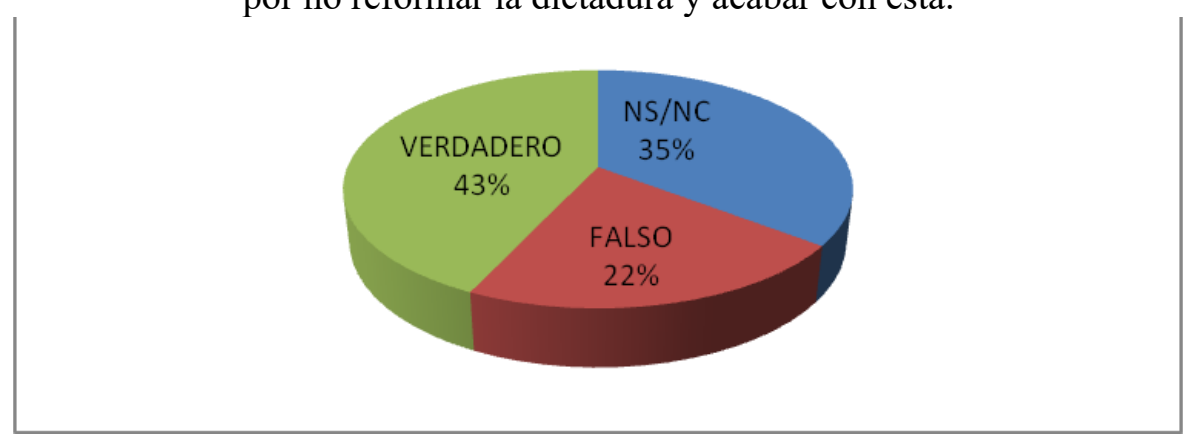

Fuente: Elaboración propia.

\subsection{Los agentes políticos, sociales y económicos}

En este apartado se presentó una pregunta en la cual las personas entrevistadas debían puntuar determinados acontecimientos, personajes o factores que, según su criterio, tuvieron mayor o menor importancia unos que otros. Para ello debían puntuar del 1 al 10, teniendo en cuenta que 1 sería el menos importante y 10 el de mayor importancia. Para analizar los resultados obtenidos se ha sumado la puntuación de cada agente presentado. El resultado salta a la vista en el siguiente gráfico: la mayor puntuación, con 534 puntos y casi 100 de diferencia con el segundo y tercer puesto, corresponde a la muerte del dictador; es decir, los resultados constatan que para el alumnado entrevistado la desaparición física de Franco es la primera causa que posibilitó el final de la dictadura. Como ya se ha mencionado en páginas anteriores éste no fue el factor principal, pero sigue siendo percibido como si lo fuese. Los dos siguientes factores, prácticamente empatados, han sido la crisis económica y las diferentes organizaciones armadas antifranquistas. Los cuatro agentes menos votados, de menor a mayor, han sido los sectores internos de la dictadura, la coyuntura internacional, Juan Carlos de Borbón y la burguesía reformista.

En cambio, cuando se les consulta si sectores económicos, tales como la burguesía o la oligarquía, no estaban cómodos dentro de la dictadura y estaban a favor de acabar con ella, casi un $48 \%$ está de acuerdo o totalmente de acuerdo, por un $25 \%$ que está en desacuerdo o totalmente desacuerdo. Sin embargo, comparando estas respuestas con el gráfico anterior comprobamos cierta contradicción, debido a que en aquella se observa que la burguesía reformista ha quedado en sexto lugar sobre diez posibles. 
Preguntando si el movimiento obrero, que en el Gráfico 17 se encuentra en cuarto lugar empatado con los partidos políticos, tuvo gran incidencia política durante la transición y fue un actor principal, un 54\% está de acuerdo o totalmente de acuerdo en señalar la importancia del movimiento obrero en la transición española, mientras que, únicamente, un 15\% está en desacuerdo o totalmente en desacuerdo en que el movimiento obrero fue un actor principal en aquellos años. Estas respuestas, a diferencia de las obtenidas acerca de la burguesía y la oligarquía, sí están en sintonía con las respuestas mostradas en el Gráfico 17.

GRÁFICO 17. Marca por orden de importancia del 1 al 10 (siendo 1 el menos importante y 10 el más importante), los siguientes acontecimientos, personajes o factores que posibilitaron el final de la dictadura.

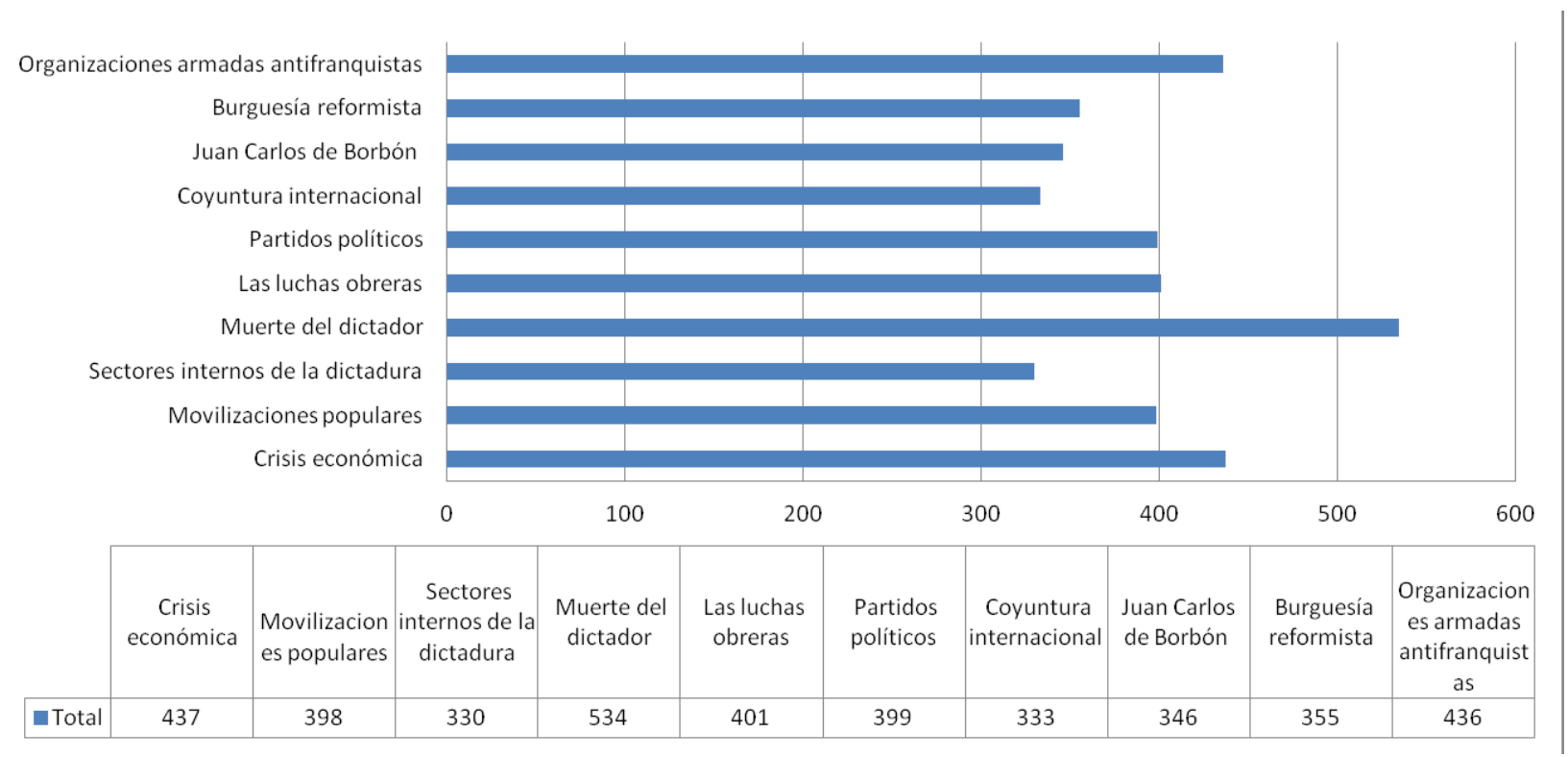

Fuente: Elaboración propia.

GRÁFICO 18. Diversos sectores económicos, como la burguesía o la oligarquía financiera, no estaban contentos con la dictadura y querían su fin.

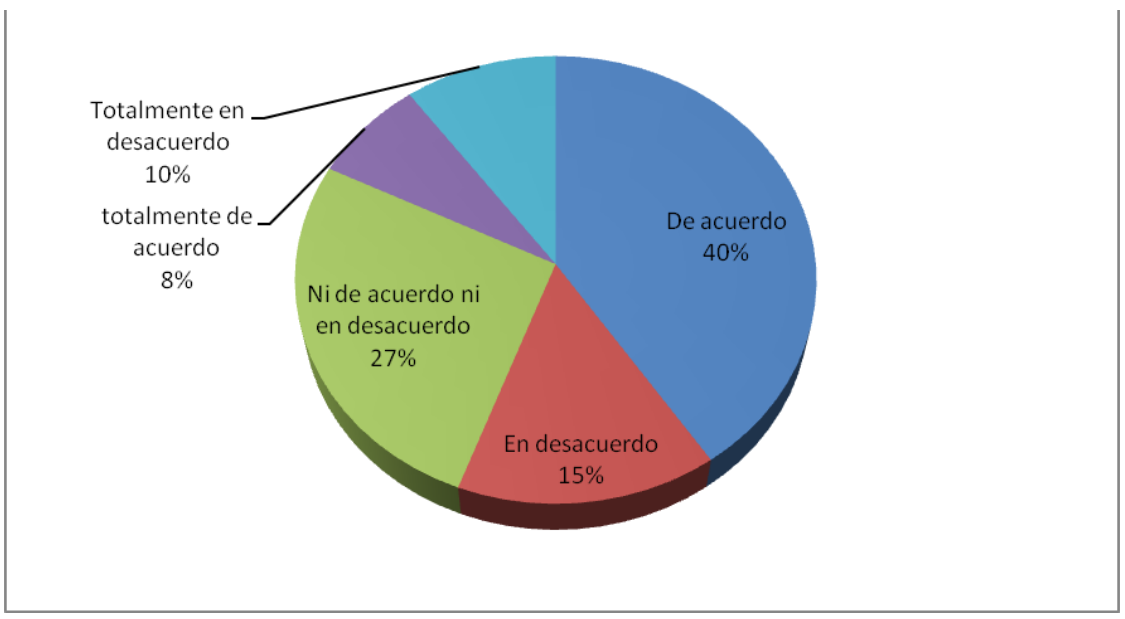

Fuente: Elaboración propia. 
GRÁFICO 19. El movimiento obrero tuvo una gran incidencia política en aquella época y fue un actor principal.

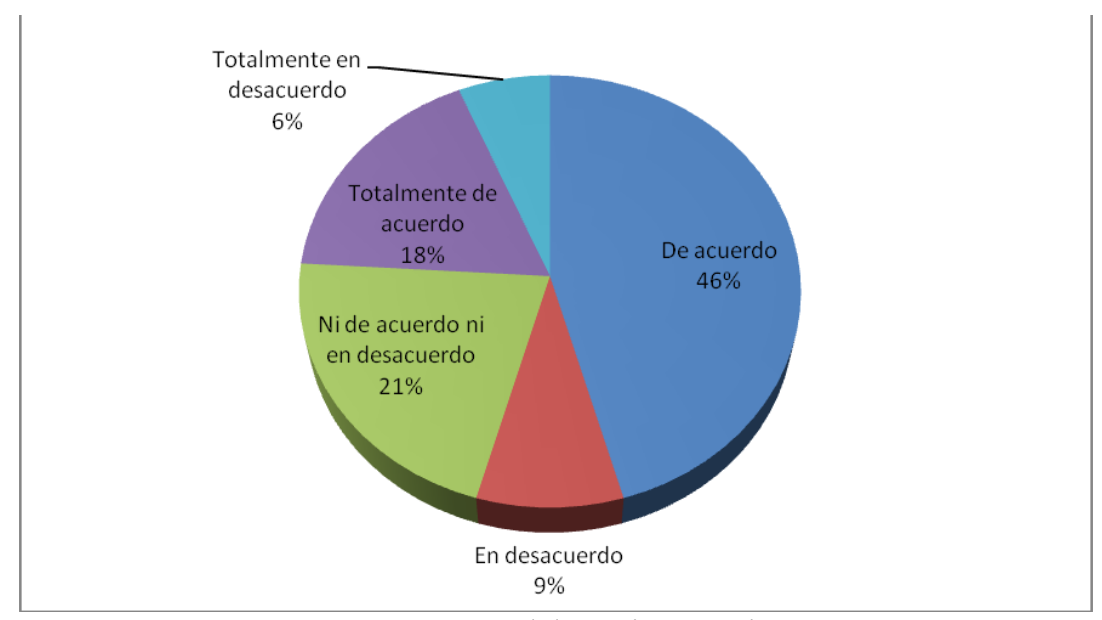

Fuente: Elaboración propia.

Incidiendo en las preguntas planteadas anteriormente, se proyectó otra parecida con el objetivo de comprobar posibles contradicciones mediante la realización de preguntas semejantes. Es el caso de la afirmación planteada en el Gráfico 20 -siguiente página-, en la que el alumnado debía indicar un único actor, el que creyesen que más habían promovido el final de la dictadura y por consiguiente la transición. En esta cuestión ha habido un problema en una cantidad importante de respuestas y es que, muchas personas, un $21 \%$, han señalado más de un actor.

El actor que creen que más impulsó para que se diese la transición ha sido el de los antifranquistas con un 27\%; seguido de lejos -un 13\%- la población en general. Los reformadores franquistas $-9 \%$-, las élites económicas $-6 \%$ - y las élites políticas $-4 \%$ - son los actores con menor selección. Según esta cuestión, se puede llegar a la conclusión que el alumnado encuestado ve en la oposición antifranquista y en la población a los actores que posibilitaron o impulsaron la transición española. Estas respuestas están en concordancia con las obtenidas en el Gráfico 17, en donde las organizaciones armadas antifranquistas y las movilizaciones populares estaban en los primeros puestos, y la burguesía y los sectores internos de la dictadura ocupaban algunos de los últimos puestos.

GRÁFICO 20. Indica cuál de estos actores crees que más impulsaron para que se diese la transición.

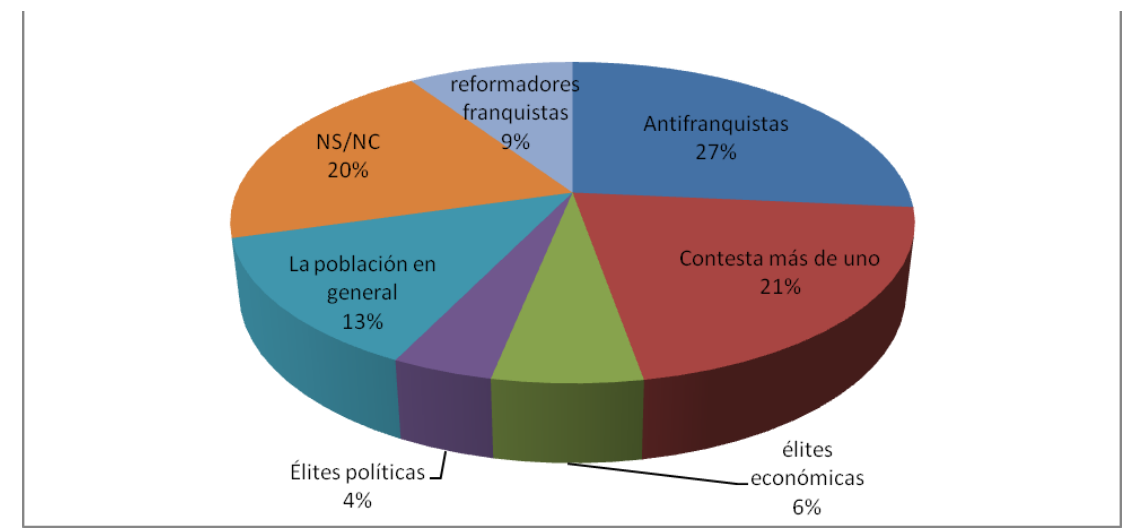

Fuente: Elaboración propia. 
GRÁFICO 21. Indica cuál de estos actores crees que más impulsaron para que se diese la transición (todas las respuestas).

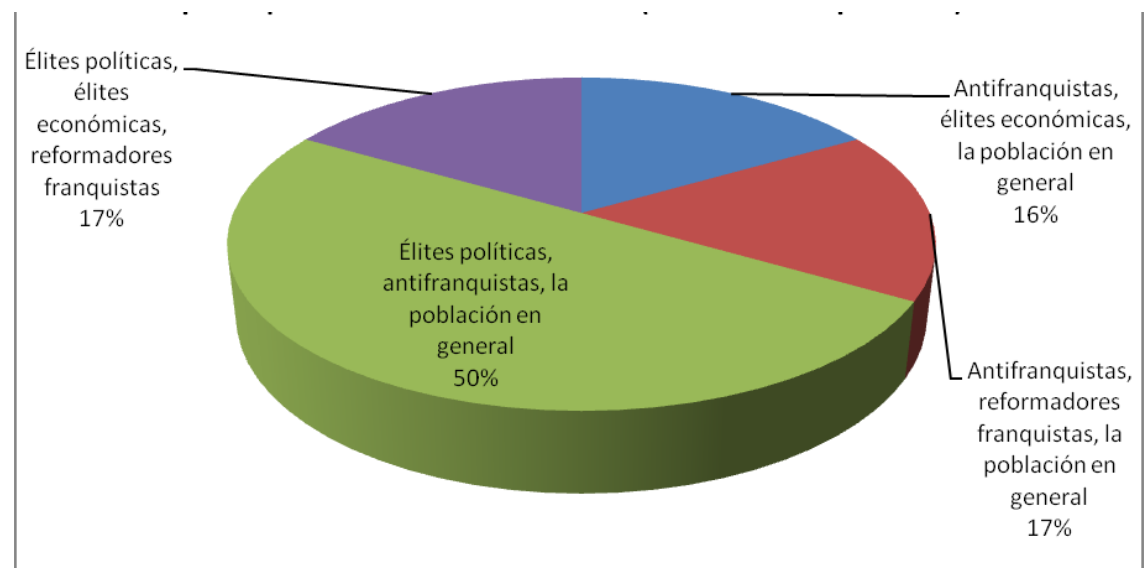

Fuente: Elaboración propia.

En el Gráfico 21 se ha realizado un agrupamiento con todas las opciones marcadas para, de este modo, integrar las respuestas del 21\% que marcó más de una opción. Observando dicho gráfico, un $83 \%$ señala a los antifranquistas y a la población en general como los actores principales. Con ello se comprueba que para el alumnado encuestado la sociedad en su conjunto, organizada o no, fue determinante para llegar a la transición. Únicamente un $17 \%$ indica tanto a los sectores internos de la dictadura como a diversos poderes fácticos, como las élites políticas o económicas; no obstante un $67 \%$ señala a las élites políticas, sin las económicas las cuales son señaladas por un $33 \%$.

Posiblemente la gran contradicción llega cuando se plantea una cuestión directa sobre ETA. Hay que tener en cuenta que esa organización era antifranquista y que usaba la violencia política. Si nos atenemos a las respuestas obtenidas anteriormente, acerca de las organizaciones armadas antifranquistas, a la pregunta sobre si ETA fue la principal amenaza de la transición, a priori podría suponerse que la respuesta sería negativa. Sin embargo, hay una cierta división equitativa en la respuesta: un 39\% está de acuerdo o totalmente de acuerdo en que ETA fue la principal amenaza de la transición; un $31 \%$ está en desacuerdo o totalmente en desacuerdo con esa afirmación; y un 30\% ni está de acuerdo ni en desacuerdo.

GRÁFICO 22. ETA fue la principal amenaza de la transición.

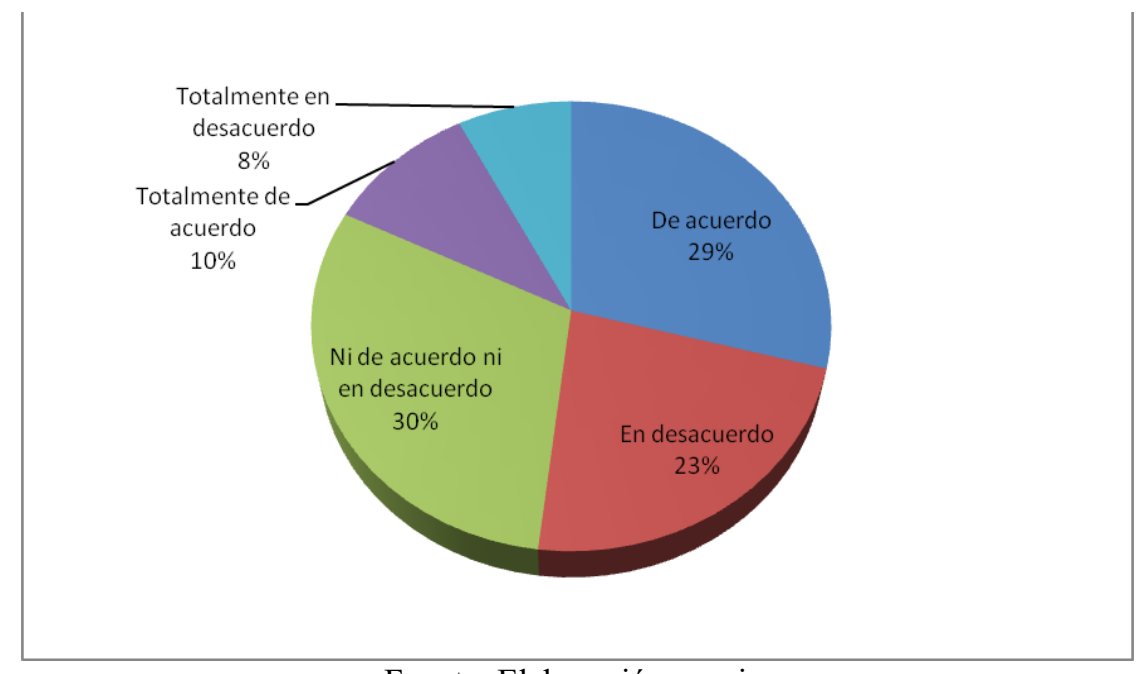

Fuente: Elaboración propia. 
GRÁFICO 23. ETA fue la principal amenaza de la transición (respuestas por origen).

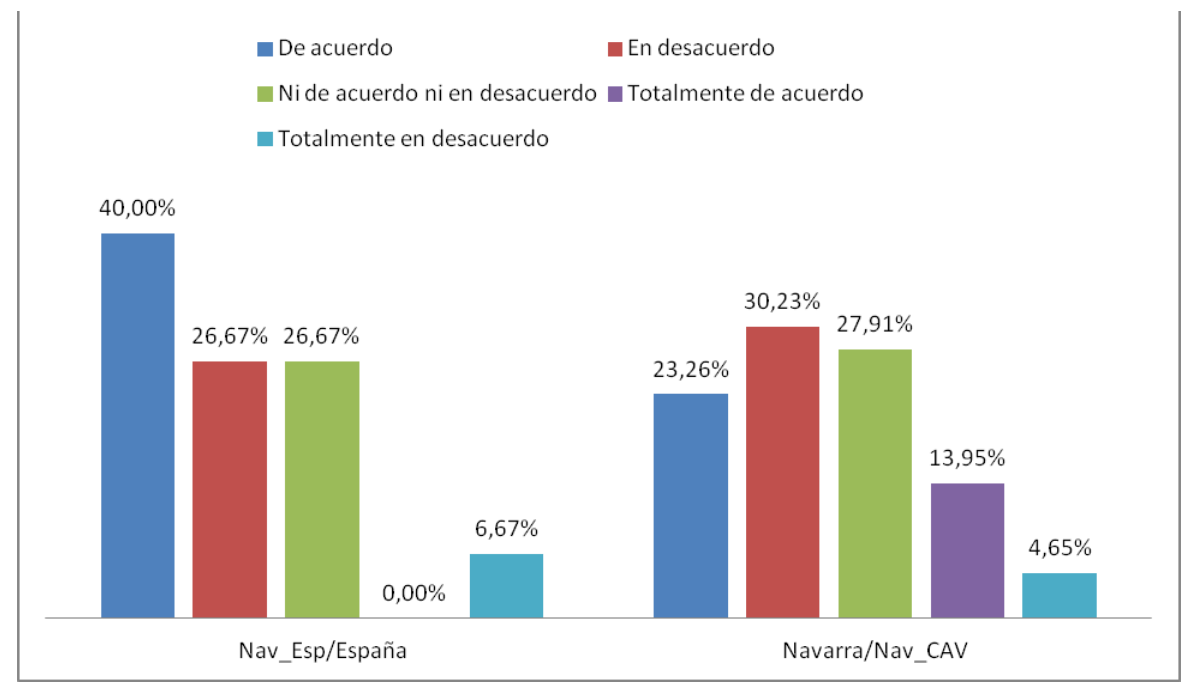

Fuente: Elaboración propia.

Cuando se desglosa por origen, para casi un $37 \%$ de quienes tienen origen vasconavarro ETA sí fue la principal amenaza de la transición; por el contrario casi un 35\% está en desacuerdo o totalmente en desacuerdo. Es decir, existe prácticamente un empate técnico entre quienes creen que ETA si fue la principal amenaza y quienes creen que no. En el caso de las personas con al menos un progenitor del resto del Estado, un 40\% está de acuerdo en que ETA fue la principal amenaza por más de un 33\% que cree lo contrario, prácticamente los mismos resultados que en la encuesta global.

\subsection{Valoración global de la transición.}

Tal y como se ha mencionado con anterioridad, el relato hegemónico durante muchos años ha presentado el periodo de la transición española como pacífico y modélico, a la vez que exportable. Esta visión sigue presente en parte de la historiografía española $\mathrm{y}$, más aún, en los medios de comunicación.

Al preguntar al alumnado de $1^{\circ}$ de bachillerato que niveles de acuerdo o de desacuerdo tienen en cuanto a la afirmación de que la transición fue pacífica y modélica, un $45 \%$ del alumnado dijo estar en desacuerdo ante esa afirmación y casi un $20 \%$ está totalmente en desacuerdo, es decir casi un $65 \%$ del alumnado encuestado cree que la transición española no fue ni pacífica ni modélica. Por el contrario, únicamente un $9 \%$ está de acuerdo o totalmente de acuerdo en calificar este periodo como pacífico y modélico.

GRÁFICO 24. La transición fue pacífica y modélica.

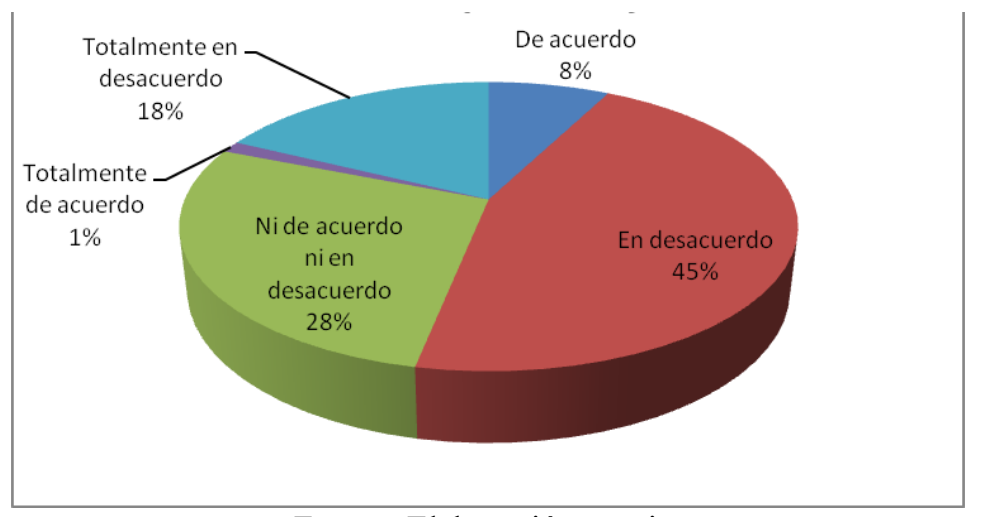

Fuente: Elaboración propia. 
GRÁFICO 25. La transición fue pacífica y modélica (respuestas por origen).

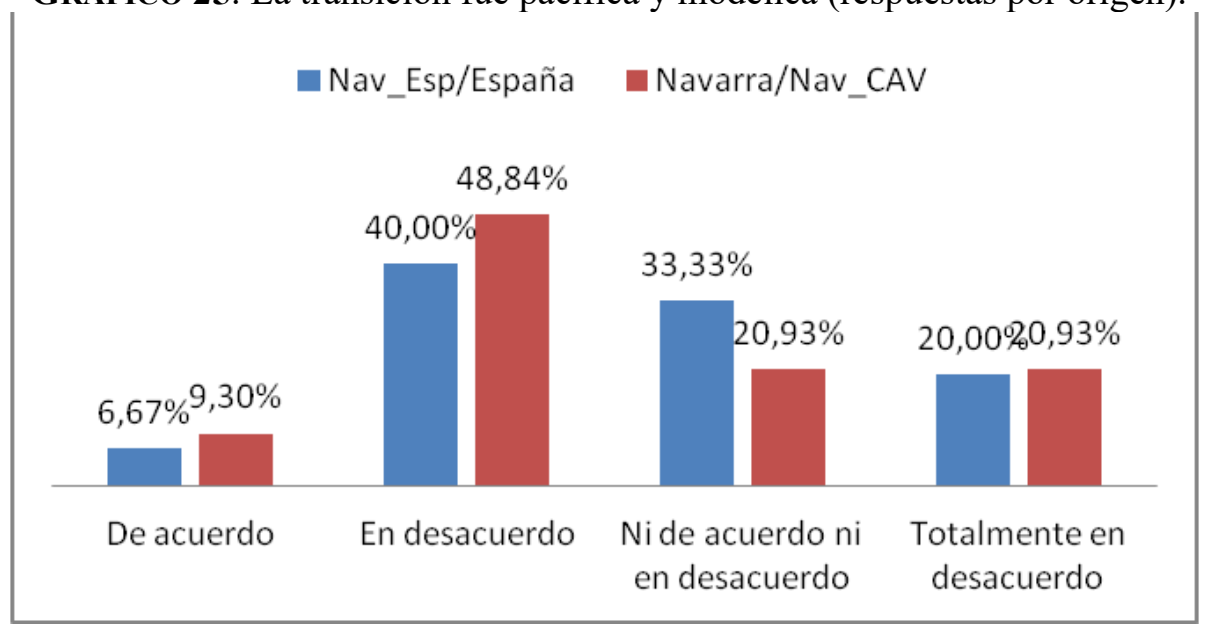

Fuente: Elaboración propia.

Entre el alumnado de origen vasconavarro la opinión de que la transición no fue ni pacífica ni modélica es casi del 70\%, es decir, 5 puntos superior a la media. El porcentaje de quienes sí creen que fue pacífica y modélica es similar a la media total del alumnado. El otro grupo analizado en el Gráfico 32, también cree mayoritariamente -un 60\%- que la transición no fue ni pacífica ni modélica; pese a ello es casi $5 \%$ inferior al conjunto total.

Estos resultados coinciden con la mayoría de respuestas obtenidas en otras preguntas en las cuales se consultaba acerca de la violencia en la transición, y especialmente de la violencia estatal.

Al plantear si la transición fue democrática se encuentran más divergencias. Por un lado, un $40 \%$ está en desacuerdo o totalmente en desacuerdo en calificar la transición española como democrática, por un 33\% que sí la denominaría de ese modo. Por origen, tal y como se observa en el Gráfico 34, en el primer grupo un $60 \%$ está en desacuerdo o totalmente en desacuerdo en definir la transición como democrática, superando en 20 puntos la media global; por el contrario, aproximadamente un 33\% está de acuerdo o totalmente de acuerdo. El segundo grupo presenta resultados muy diferentes. En cuanto a designarla como democrática, aproximadamente un $37 \%$ dice que está en desacuerdo o totalmente en desacuerdo, 3 puntos por debajo de la media. Mientras, casi un $43 \%$ está de acuerdo o totalmente de acuerdo, 10 puntos por encima de la media. Estas respuestas contradicen, en cierta medida, la definición de "democrática" que en la pregunta reflejada en el Gráfico 3 ocupa la tercera posición.

GRÁFICO 26. La transición democrática.

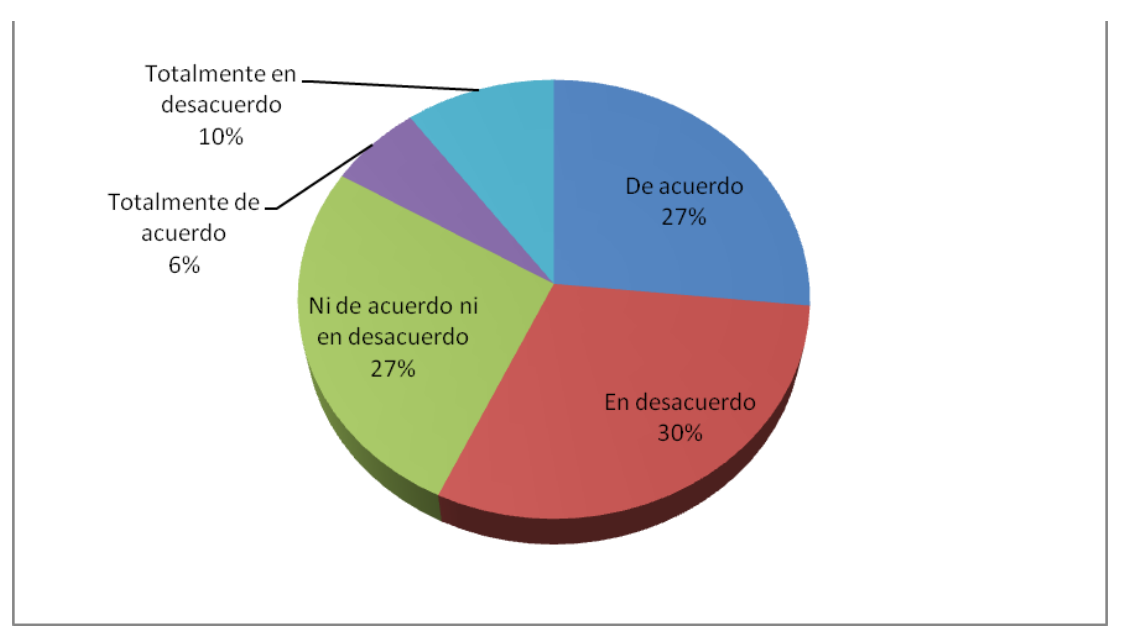

Fuente: Elaboración propia. 
GRÁFICO 27. La transición fue democrática (respuestas por origen).

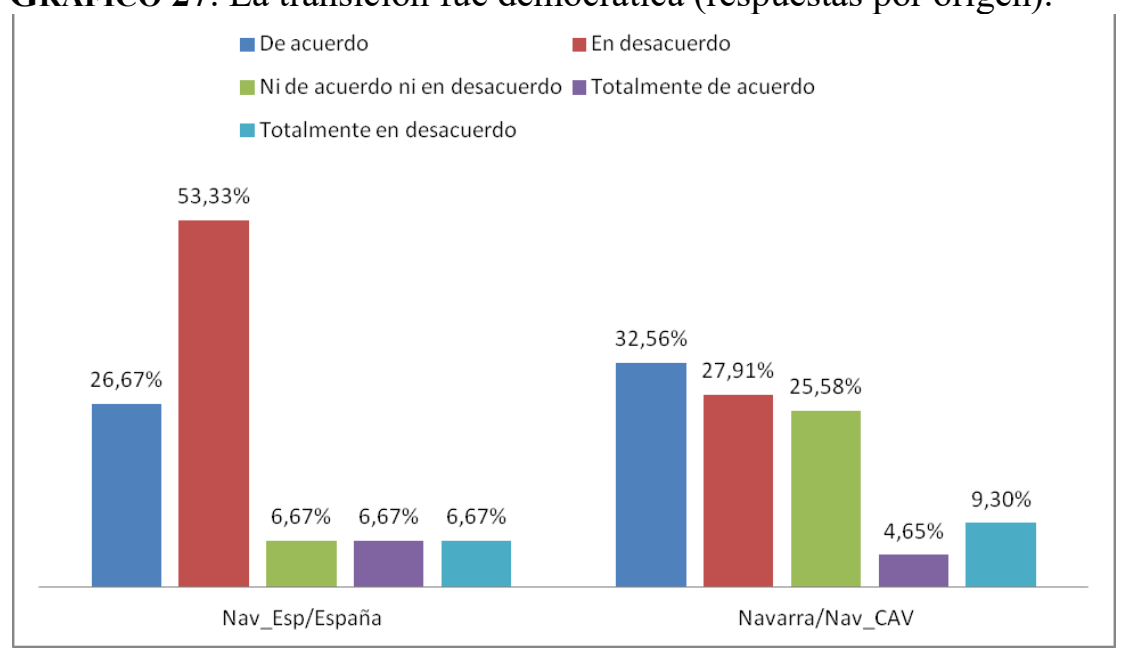

Fuente: Elaboración propia.

\section{Conclusiones}

El proceso histórico de la transición española, que sucedió en la década de 1970, influye directamente en el día a día de la actualidad. El régimen político actual emana directamente de aquel hecho histórico, por lo que su conocimiento ayuda al entendimiento del presente político, social y económico. Por ello, debería ser de capital importancia la enseñanza y aprendizaje de ese tiempo histórico, con el objetivo de crear una ciudadanía crítica. No obstante, aquel periodo tiene reservado la última parte del currículo del último año de la E.S.O., lo que provoca que esa materia se imparta deprisa y con menor dedicación, en el mejor de los casos, en comparación con otros periodos.

Tal y como se ha podido comprobar a lo largo de este artículo, el alumnado encuestado sí posee, en general, unas ideas o conocimientos acerca de la transición española. No lo es menos que varias de esas ideas que poseen están plagadas de contradicciones o inexactitudes. También ostenta algunas visiones que desde el hegemonismo político se han ido construyendo durante las décadas posteriores y que parte de la historiografía actual ha desmontado. Esto se observa claramente en lo referente al papel desempeñado por actores concretos -como Juan Carlos de Borbón o Adolfo Suárez- o por colectivos como el movimiento obrero o la burguesía, en donde se sobredimensiona el papel de unos y se minusvalora el de otros. No obstante, el alumnado encuestado es mayoritariamente contrario a definir la transición española como pacífica y modélica, indicando, por el contrario, que se trató de un periodo caracterizado por la violencia en la que el Estado tuvo una implicación muy activa. En esa visión global parece que sí se ha avanzado. Por el contrario, mientras por un lado definen la transición como democrática, por otro existe una división de opiniones al respecto.

Asimismo, el alumnado encuestado relaciona el nombre de Franco a la dictadura y los de Suárez y Juan Carlos de Borbón directamente al régimen democrático, existiendo una gran confusión, o desconocimiento, cuando deben relacionar estos personajes en el contexto histórico. Una gran contradicción observada es que poseen la idea de que Suárez y Juan Carlos de Borbón fueron los promotores de la transición cuando se les pregunta directamente por ellos, pero, en cambio, esta visión ya no es la misma cuando se les presentan otros actores históricos como la oposición antifranquista.

En definitiva, esta investigación muestra que el alumnado encuestado sí posee ciertas ideas o conocimientos respecto de la transición, algunos de ellos gratamente sorprendentes; no obstante, se evidencian carencias de comprensión y relación entre determinados actores históricos y los diferentes tiempos históricos en los que desenvolvieron su actividad. 


\section{Referencias}

Andrade Blanco, J. A. (2012). El PCE y el PSOE en (la) transición. La evolución ideológica de la izquierda durante el proceso de cambio político. Madrid: Siglo XXI.

Andre-Bazzana, B. (2006). Mitos y mentiras de la Transición. Ed. El Viejo Topo.

Avilés, J. (2005). Democracia y terrorismo en España. En C. Waisman (comp.). Transiciones de la dictadura a la democracia: los casos de España y América Latina (pp. 167-185). Zarautz: $\mathrm{UPV} / \mathrm{EHU}$.

Bardavío, J. (2017). El camino a la democracia. $A B C$. Recuperado de http://www.abc.es/espana/latransicion-espanola/abci-primeras-elecciones-201706082108_noticia.html [13 de septiembre de 2018].

Bueno Urritzelki, M. (2016). Amnistía '77. La lucha del pueblo vasco. Buenos Aires: Lauburu.

Casals, X. (2016). La transición española. El voto ignorado de las armas. Barcelona: Pasado y Presente.

Casanellas, P. (2014). Morir matando. El franquismo ante la práctica armada. 1968-1977. Madrid: Catarata.

Castells, L. y Rivera, A. (2015). Las víctimas del victimismo construido a las víctimas reales. En F. Molina y J.A. Pérez (eds.). El peso de la identidad. Mitos y ritos de la historia vasca (pp.264305). Madrid: Marcial Pons.

Castells, M. (1982). Radiografía de un modelo represivo. San Sebastián: Ediciones vascas.

Cebrián, J. L. (2017). El triunfo de un modelo. El País. Recuperado de http://politica.elpais.com/politica/2017/06/13/actualidad/1497365138_382933.html [18 de septiembre de 2018].

Cuesta, J. (2007). Recuerdo, silencio y amnistía en la transición y en la democracia española (19752006). Estudios Historia contemporánea, 25, 125-165.

Euskal Memoria. (2010). No les bastó Gernika. Euskal Herria 1960-2010. Andoain.

Fontana, J. (2017). El siglo de la revolución. Una historia del mundo desde 1914. Barcelona: Crítica.

García San Miguel, L. (1981). Teoría de la transición. Un análisis del modelo español 1973-1978. Madrid: Editora Nacional.

López, R. y Pérez, J. A. (2011). Los movimientos sociales y el abertzalismo radical durante la transición en el País Vasco. En Quirosa-Cheyrouze Muñoz, R. (ed.). La sociedad española en la transición. Los movimientos sociales en el proceso democratizador (pp. 317-330). Madrid: Biblioteca Nueva.

López, J. J. (2017). La transacción de la transición. La Vanguardia. Recuperado de http://www.lavanguardia.com/opinion/20170415/421698876886/la-transaccion-de-latransicion.html [18 de septiembre de 2018].

Maravall, J.M. (1989). Transición política y consolidación de la democracia en España. En J. F.Tezanos (ed.). La transición democrática española (pp. 183-249). Madrid: Ed. Sistema.

Molinero, C. e Ysàs, P. (2018). La transición. Historia y relatos. Madrid: Ed. Siglo XXI.

Olarieta Alberdi, J. M. (1990). Transición y represión política. Revista de estudios políticos, 70.

Pegenaute, P. (2017). Los 40 años de nuestra democracia. Diario de Navarra. Recuperado de http://www.diariodenavarra.es/participacion/cartasaldirector/contenidos/8d5e0_los-anosnuestra-democracia-1674-109.html [27 de septiembre de 2018].

Pérez, J. A. y López, R. (2015). La memoria histórica del franquismo y la Transición. En Molina, F. y Pérez, J.A. (eds.). El peso de la identidad. Mitos y ritos de la historia vasca (pp. 225-263). Madrid: Marcial Pons.

Pinilla, A. (2017). Aquellas elecciones de hace 40 años. $A B C$. Recuperado de http://www.abc.es/espana/la-transicion-espanola/abci-aquellas-elecciones-hace-40-anos201706150331_noticia.html [27 de septiembre de 2018].

Powell, C. (2002). España en democracia 1975-2000. Las claves de la profunda transformación de España. Barcelona: Ed. Debolsillo. 
Preston, P. (2001). El triunfo de la democracia en España. Barcelona: Ed. Grijalbo.

Redero San Román, M. (1993). Transición a la democracia y poder político en la España postfranquista (1975-1978). Salamanca: Librería Cervantes.

Redero San Román, M. (ed.). (1996). La transición a la democracia en España. Madrid: Ed. Marcial Pons.

Rodriguez, E. (2015). Por qué fracasó la democracia en España. La Transición y el régimen del '78. Madrid: Traficantes de sueños.

Sartorius, N., y Sabio, A. (2007). El final de la dictadura. Madrid: Temas de Hoy.

Soto, Á. (1996). La transición a la democracia. España 1975-1986. Madrid: Alianza Editorial.

Tusell, J. (1991). La transición española a la democracia. Madrid: Historia16.

Wilhelmi, G. (2016). Romper el consenso. La izquierda radical en la Transición española (19751982). Madrid: Siglo XXI.

CÓMO CITAR ESTE ARTÍ́CULO

Bueno, M. y Arcocha, E. (2020). La transición española: ¿qué sabe el alumnado de $1^{\circ}$ de bachillerato? Didáctica de las ciencias experimentales y sociales, 38, 39-60. DOI: 10.7203/DCES.38.13700. 


\section{ANEXO \\ CUESTIONARIO REALIZADO POR EL ALUMNADO}

1. Indica tu identidad de género:

$\square$ Femenino $\quad$ Masculino $\square$ Transgénero

2. ¿Cuál es el país o comunidad autónoma de origen de tu(s) madre(s) y/o padre(s)?

3. Señala en dónde has obtenido algún tipo de información sobre la transición española.
$\square$ En el instituto
$\square$ En los medios de comunicación
$\square$ En conversaciones familiares
$\square$ En libros
$\square$ No sabe/ No contesta

$\square$ En series y películas

4. Elige tres términos que, según tú, definan el periodo de la transición.
$\square$ Violenta
$\square$ Pacífica
$\square$ Democrática
Consenso
$\square$ Reforma
$\square$ Ruptura
$\square$ Anti-democrática
$\square$ Discordancia

$\square$ No sabe/ No contesta

5. Indica cuál de estos actores crees que más impulsaron para que se diese la transición.
$\square$ Élites políticas
$\square$ Élites económicas
$\square$ La población en general
$\square$ Antifranquistas
$\square$ Reformadores franquistas
$\square$ No sabe/ No contesta

6. ¿Quién fue el último presidente del Gobierno de la dictadura?
$\square$ Francisco Franco
$\square$ Luis Carrero Blanco
$\square$ Carlos Arias Navarro
$\square$ Adolfo Suárez
$\square$ Juan Carlos de Borbón
$\square$ No sabe/ No contesta

7. ¿Quién fue el primer presidente del Gobierno tras el final de la dictadura?
$\square$ Carlos Arias Navarro
$\square$ Juan Carlos de Borbón
$\square$ Adolfo Suárez
$\square$ Felipe González
$\square$ Manuel Fraga
$\square$ No sabe/ No contesta

8. Marca por orden de importancia del 1 al 10 (siendo 1 el menos importante y 10 el más importante), los siguientes acontecimientos, personajes o factores que posibilitaron el final de la dictadura:
$\square$ Crisis económica
$\square$ Movilizaciones populares
$\square$ Sectores internos de la dictadura
$\square$ Muerte del dictador
$\square$ Las luchas obreras
$\square$ Partidos políticos

$\square$ Coyuntura internacional $\square$ Juan Carlos de Borbón

$\square$ Burguesía reformista

$\square$ Organizaciones armadas antifranquistas

9. ¿Quién decidió que Juan Carlos I fuese rey de España y Jefe del Estado?
$\square$ Francisco Franco
$\square$ Adolfo Suárez
$\square$ El propio Juan Carlos I
$\square$ Se decidió en referéndum popular específico
$\square$ No sabe/ No contesta

10. Responde si crees que son verdaderas o falsas las siguientes afirmaciones. También puedes dejar sin responderla señalando la casilla No sabe/No contesta.

- El Estado creó grupos armados ilegales para enfrentarse a sus adversarios políticos.

$\square$ Verdadero $\quad \square$ Falso $\square$ No sabe/ No contesta

- Acontecimientos internacionales ocurridos en aquellos años, como la Revolución de los Claveles en Portugal o la caída de la Dictadura de los Coroneles en Grecia, fueron determinantes para que algunos personajes, como el rey Juan Carlos I, optasen por no reformar la dictadura y acabar con esta.
$\square$ Verdadero
$\square$ Falso
$\square$ No sabe/ No contesta

- El pueblo decidió en referéndum que el Estado fuese una monarquía parlamentaria y no una república.

$\square$ Verdadero $\quad \square$ Falso $\square$ No sabe/ No contesta

- Grupos de ultraderecha y el terrorismo de Estado causaron más de 300 muertos durante la transición.

$\square$ Verdadero $\quad \square$ Falso $\quad \square$ No sabe/ No contesta 
- En Navarra, en 1977, todos los partidos políticos, salvo los de derechas, estaban a favor de una unión con la actual Euskadi.
$\square$ Verdadero
$\square$ Falso
$\square$ No sabe/ No contesta

- Navarra vivió varios acontecimientos muy conflictivos (Montejurra, Semana pro-Amnistía, Sanfermines’78), con muertos y heridos, provocados por las Fuerzas de Seguridad del Estado (policía) y grupos armados de extrema derecha.

$\square$ Verdadero

$\square$ Falso

$\square$ No sabe/ No contesta

- En 1977 el Ayuntamiento de Pamplona decidió colocar la ikurriña en el balcón junto a las banderas de Pamplona, Navarra y España.

$\square$ Verdadero $\square$ Falso $\square$ No sabe/ No contesta

- El Estatuto de Autonomía de Navarra, llamado Amejoramiento, fue aprobado en referéndum.

$\square$ Verdadero $\quad \square$ Falso $\quad \square$ No sabe/ No contesta

- El primer presidente de la Comunidad Autónoma Vasca (Euskadi) fue un navarro.

$\square$ Verdadero $\square$ Falso $\square$ No sabe/ No contesta

11. Lee las siguientes afirmaciones e indica en qué grado estás de acuerdo o en desacuerdo. - La transición fue pacífica y modélica.

$\square$ Totalmente en desacuerdo $\square$ En desacuerdo $\quad \square$ Ni de acuerdo ni en desacuerdo

$\square$ De acuerdo $\quad \square$ Totalmente de acuerdo

- El rey Juan Carlos I siempre tuvo como proyecto político la restauración democrática.
$\square$ Totalmente en desacuerdo
$\square$ En desacuerdo
$\square \mathrm{Ni}$ de acuerdo ni en desacuerdo

$\square$ De acuerdo

$\square$ Totalmente de acuerdo

- ETA fue la principal amenaza de la transición.
$\checkmark$ Totalmente en desacuerdo
$\square$ En desacuerdo
$\square$ Ni de acuerdo ni en desacuerdo
$\square$ De acuerdo
$\square$ Totalmente de acuerdo

- Juan Carlos I y Adolfo Suárez fueron quienes hicieron posible la transición.
$\square$ Totalmente en desacuerdo
$\square$ En desacuerdo
$\square \mathrm{Ni}$ de acuerdo ni en desacuerdo
$\square$ De acuerdo
$\square$ Totalmente de acuerdo

- Diversos sectores económicos, como la burguesía o la oligarquía financiera, no estaban contentos con la dictadura y querían su fin.
$\square$ Totalmente en desacuerdo
$\square$ En desacuerdo
$\square$ Ni de acuerdo ni en desacuerdo
$\square$ De acuerdo
$\square$ Totalmente de acuerdo

- El movimiento obrero tuvo una gran incidencia política en aquella época y fue un actor principal.
$\square$ Totalmente en desacuerdo
$\square$ En desacuerdo
$\square \mathrm{Ni}$ de acuerdo ni en desacuerdo
$\square$ De acuerdo
$\square$ Totalmente de acuerdo

- La transición fue democrática.

$\square$ Totalmente en desacuerdo

$\square$ De acuerdo

$\square$ En desacuerdo $\quad \square$ Ni de acuerdo ni en desacuerdo
$\square$ Totalmente de acuerdo 